\title{
AN IMPROVED APPARATUS AND METHOD FOR THE ANALYSIS OF GAS MIXTURES BY COMBUSTION AND ABSORPTION
}

\author{
By Martin Shepherd
}

ABSTRACT

This paper describes an improved volumetric apparatus for the analysis of gases by combustion and absorption methods. The apparatus is of the type which has a series of pipettes connected to the burette and is commonly called an "Orsat." The operating technique is given in a set of simple instructions.

While the unit is similar to many commercial forms of gas analysis apparatus, it differs in a number of details of the assembly and the construction of individual parts. The adjustment and control of pressure balances have been greatly improved. Distinct advances have been made in the designs of the combustion and absorption pipettes, and of the manometer-compensator unit. A new type of mounting permits the easy removal and replacement of any part.

The unit as a whole has been made as modern as possible. It has been found more satisfactory, both as to accuracy obtainable and ease of manipulation, than other available models.

\section{CONTENTS}

II The importan

II. The importance of apparatus design in gas analysis _........ 122

III. Description of the apparatus

1. The burette

2. The burette illuminator

3. The manometer and compensator

4. The pressure control

5. The water jacket

6. The distributor

7. The absorption pipettes

8. The combustion pipette... 135

9. The sampling pipette

10. Method of securing connections

11. The assembly

12. The apparatus support

13. Stopcocks

IV. Methods of analysis and technique of operation 143

1. Sampling ..

2. Preparation of the apparatus for an analysis

3. Considerations preliminary to the actual analysis_....... 146

4. Analytical procedure; air used for the combustion.......... 148

5. Analytical procedure; oxygen used for the combustion $\ldots .$.

6. Analytical procedure; with the calibrated manometer and distributor

7. Determination of the steps necessary for an exact analysis -

8. Calibration of the distributor and manometer.

9. Calculation of the analysis....

V. Summary

\section{INTRODUCTION}

The gas analysis unit described in this paper represents a development which occurred over a number of years, during which time the apparatus was in the hands of several investigators. It is consequently impossible to assign full credit for the present design to any one 
individual. The author desires to express his indebtedness to E. R. Weaver and P. G. Ledig, to whose work special reference is made later in the paper. He is also much indebted to E. O. Sperling, glass blower of this bureau, for many helpful suggestions. Some of the better features common to many types of so-called "Orsat" apparatus have been retained.

\section{THE IMPORTANCE OF APPARATUS DESIGN IN GAS ANALYSIS}

Gas analysis differs from other chemical analysis in the relative importance of the apparatus as compared to the procedure used in the analysis. A gas analysis unit must necessarily be comparatively extensive and complicated in order to perform a simple analysis. The effort devoted to apparatus design is an important and often a major part of the work. The present generally unsatisfactory state of gas analysis is attributable, in a considerable measure, to poorly designed apparatus. A number of very common errors of gas anàlysis are inherent in the apparatus rather than in the method used. In addition, awkward details of manipulation are too frequently encountered. The unit to be described was designed largely to correct these common faults.

\section{DESCRIPTION OF THE APPARATUS}

In describing this apparatus, each part will be discussed separately, and its advantages noted. The general assembly will then be explained. Reference will be made to drawings, which are presented with sufficient detail to permit reproduction of the apparatus in any laboratory or shop. For convenience, the assembly drawing has been lettered to correspond to the lettering of the drawings of the individual parts.

\section{THE BURETTE}

The common fault of burettes supplied with many gas analysis apparatus lies in the fact that the graduations are extended less than one-half way around the circumference. Because this system of graduation does not permit the elimination of parallax, serious errors are introduced in reading the volumes. The burette illustrated in Figure 1 is graduated according to the National Bureau of Standards specifications for volumetric burettes. ${ }^{1}$ All marks are extended slightly over half way around the circumference. Graduations corresponding to odd numbered milliliters are extended three-fourths way around, and those corresponding to even numbered milliliters are extended completely around. This system of graduation produces a burette which may be read conveniently and without parallax. The length of the graduated section of the burette is approximately $60 \mathrm{~cm}$, so that the distance between marks is about $1.2 \mathrm{~mm}$, which accords with the bureau's specifications. A burette of this size is conveniently read, and the attached stopcocks are easily accessible. If a much longer burette is used, no real gain in accuracy is obtained, and some inconvenience in reading and manipulation may be experienced.

1B. S. Circular No. 9, p. 5 . 


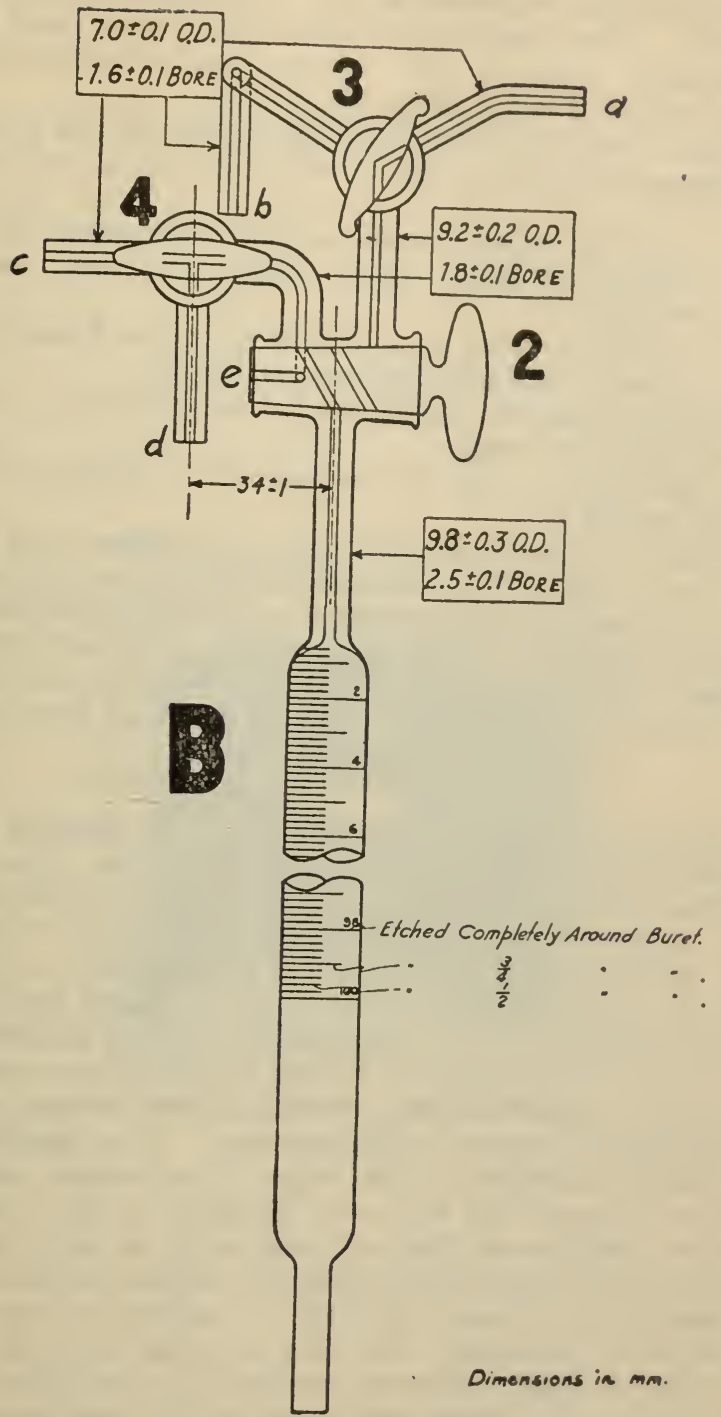

FIGURE 1.-The burette

Length of graduated section, $620 \pm 20 \mathrm{~mm}$.

Length of capillary from graduated section to bottom of stopcock $2,50 \pm 5 \mathrm{~mm}$.

Length of section from $100 \mathrm{ml}$ mark to tapered outlet, $50 \pm 10 \mathrm{~mm}$. Length of barrel of stopcock 2,40 to $43 \mathrm{~mm}$.

Diameter of key of stopcock 2, at center, 13.5 to $14.0 \mathrm{~mm}$.

Length of barrels of stopcocks $\&$ and 4,35 to $37 \mathrm{~mm}$.

Diameter of keys of stopcocks 3 and 4 , at center, 12.5 to $13 \mathrm{~mm}$.

Outlets $c$ and $d$ to be ground flat and slightly bevelled at the outer rim. 
The burette is shown in Figure 1. The pipette containing the sample to be analyzed is connected at $(a)$. A small beaker is placed under the outlet $(b)$. The distributor is connected at $(c)$ and the manometer-compensator unit at $(d)$. The system of stopcocks $2-3-4$ is designed to permit the following operations:

1. The line connecting the sampling pipette to the burette may be flushed with mercury from the burette or with a portion of the gas sample.

2. The sampling pipette may be left connected to the burette during an analysis so that a fresh sample for check analysis is immediately available.

3. Gas or mercury may be expelled from the burette, and water introduced, through the atmospheric outlet $(b)$.

4. The burette may be connected to the distributor, or the manometer, or both simultaneously.

5. The distributor may be purged with nitrogen through the atmospheric outlet (e).

The burette is calibrated to $0.2 \mathrm{ml}$, and readings may be estimated to $0.05 \mathrm{ml}$ or closer. The tolerance is $0.1 \mathrm{ml}$ per $100 \mathrm{ml}$. If more accurate measurements are necessary, a burette described by Weaver and Shepherd ${ }^{2}$ may be used. This is accurate to $0.01 \mathrm{ml}$. For the investigation of gas analysis methods, a weight burette developed by Weaver and Ledig, ${ }^{3}$ which is accurate to $0.003 \mathrm{ml}$, is recommended.

\section{THE BURETTE ILLUMINATOR}

A number of observations were made of the position of a mercury meniscus with respect to a mark etched on a glass tube, using both a cathetometer and a special device employing a micrometer screw to move the meniscus. It was apparent that the precision attainable depended greatly upon conditions of illumination. The optimum condition was obtained with a diffiused light, placed back of the meniscus, in combination with a screen which produced a shadow across the meniscus in such a manner as to remove reflections and produce in effect a sharply defined black curved surface, instead of the mirror surface ordinarily observed with mercury. It is interesting to note that a vertical movement of the edge of the screen which produced this shadow changed the apparent position of the meniscus. This effect was so pronounced that a $5 \mathrm{~mm}$ shift of the edge produced a shift of 0.01 to $0.02 \mathrm{~mm}$ in the apparent position of the meniscus.

With these facts in mind, two simple reading devices were made to be used with the burette. The first of these may be used when a proper source of light is already available in the laboratory, such as a window, preferably facing northward, which can be covered with a sheet of ordinary tracing cloth. This provides excellent illumination. The simple shield shown in Figure 2 provides the shadow. It is made of sheet metal bent to fit the water jacket surrounding the burette, and is lined with black felt and finished with "optical black" lacquer. The upper edge of the slot is adjusted by hand to a position approximately one graduation above the meniscus of the mercury within the burette. Under these conditions the observer will be able to make readings of the position of the meniscus with satisfactory precision.

${ }^{2}$ E. R. Weaver and Martin Shepherd, A Burette for the Accurate Measurement of Gas Volumes without Gas Connection to a Compensator. B. S. Sci. Paper No. 559.

E. R. Weaver and P. G. Ledig, A Weight Burette for Gas Analysis, J. Am. Chem. Soc., 42, p. 1177; 1920. 
B. S. Journal of Research, RP266

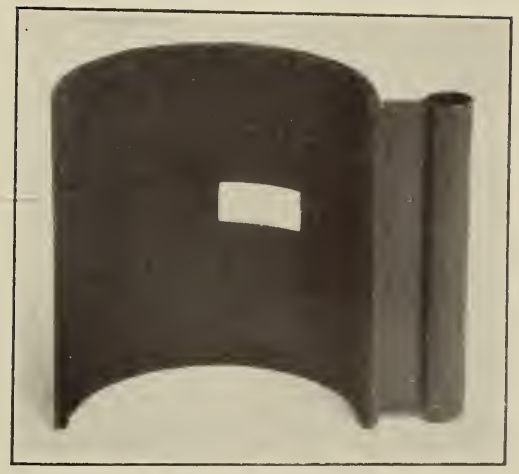

FIGURE 2.-The burette reading shield 
B. S. Journal of Research, RP266

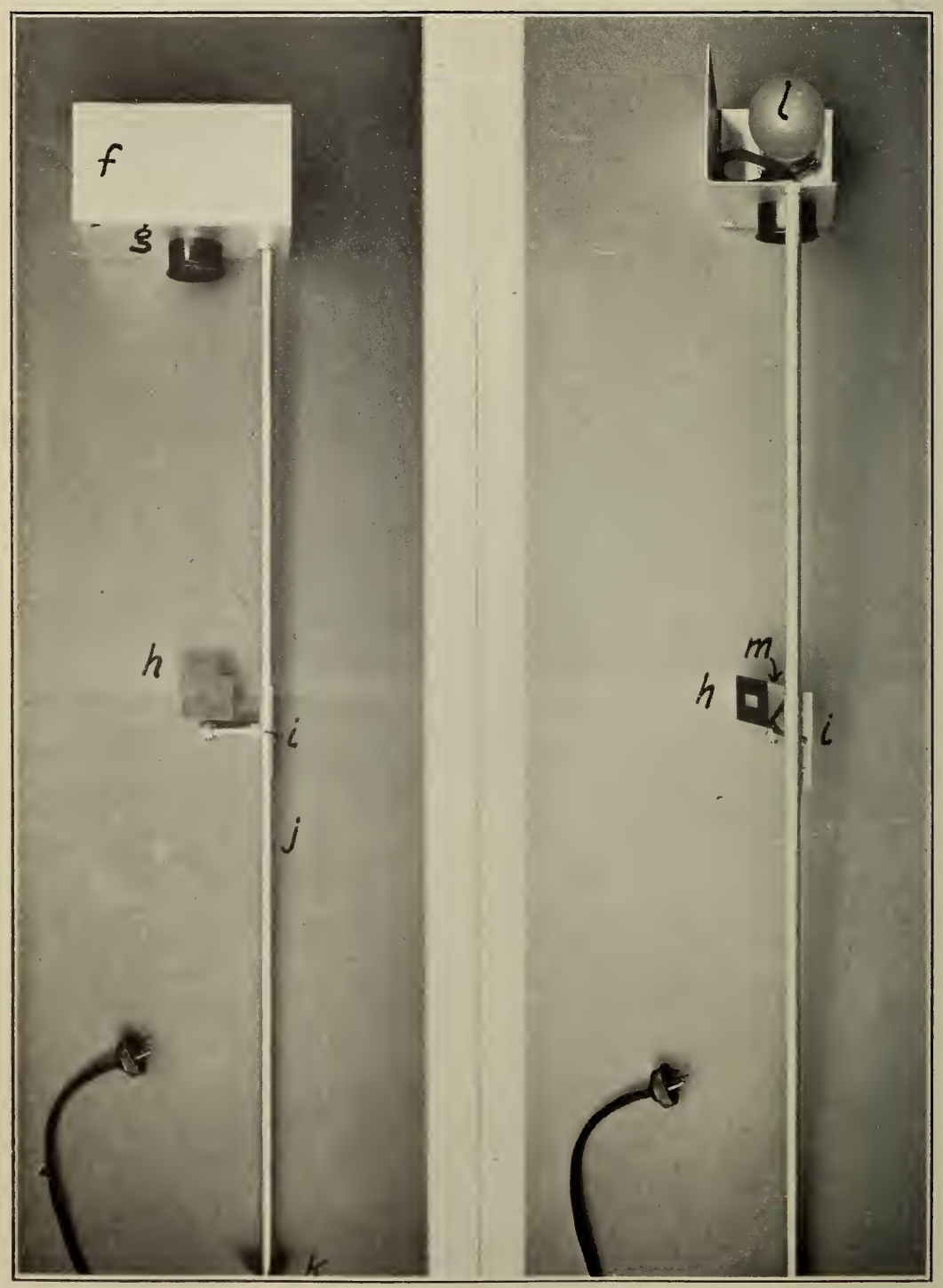

Figure 3.-The burette illuminator (front and side views) 
When the laboratory is not supplied with a suitable source of diffused light, or when the apparatus is to be carried from place to place or used at night, a lamp mounted upon the frame supporting the apparatus is very convenient. An arrangement which provides excellent illumination is shown in Figure 3. The lamp $(l)$ is mounted permanently at the top of the apparatus, and its light concentrated by a condenser lens $(g)$. The beam falls upon a sliding mirror $(\mathrm{m})$ placed at $45^{\circ}$ to the source and the burette. The front surface of the mirror is finely ground, and a slotted shield $(h)$ is placed before the mirror in order to throw a shadow upon the meniscus as before. A sheet metal shield $(f)$ shades the lamp. The mirror and shield slide freely upon the rod $(j)$, the split clamp (i) being adjusted to sufficient tension to just support their weight. The burette illuminator is fastened to the apparatus frame at $(f)$ and $(k)$.

\section{THE MANOMETER AND COMPENSATOR}

The manometer and compensator are constructed as one unit. This construction presents a number of advantages. The unit is compact and may be removed from the water jacket without disturbing the burette or distributor. It is much less fragile than the usual type. Connection from the compensator to the atmosphere is made without the ordinary stopcock. Other advantages will become apparent after a study of the detailed drawing of the upper part of the manometercompensator unit, shown in Figure 4. .

The balance point of the manometer is obtained by electric contact. This method was suggested by Gregg ${ }^{4}$ and its accuracy determined by Weaver and Ledig, ${ }^{5}$ but it has not received the attention it merits. For the purpose used here it is by far the most satisfactory means of adjusting the pressure to a zero or fixed reference point with respect to both accuracy and ease of manipulation. A platinum lead $(o)$ is sealed into the arm of the manometer adjacent to the compensator and passes through a small tube $(q)$ in the dome of the compensator. A platinum contact $(n)$, sharpened and polished to a needle point, is supported by the sleeve $A$ so that it centers within the same arm of

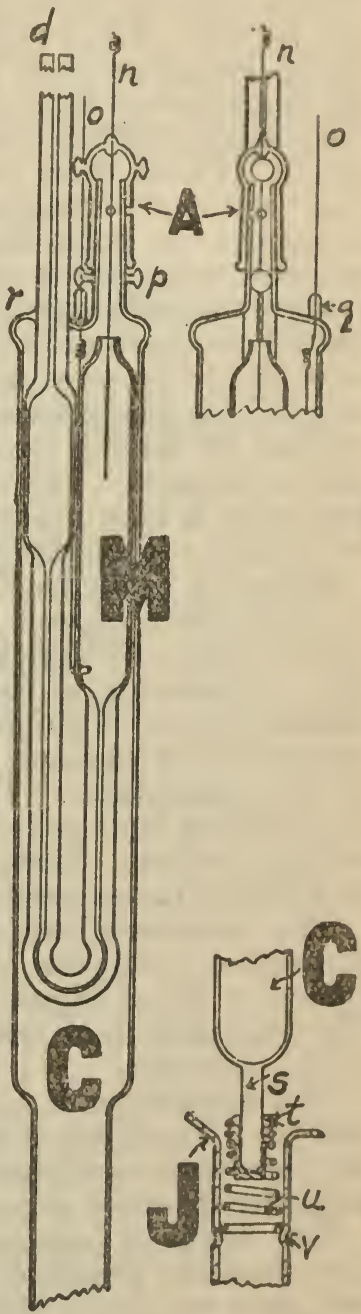

Figure 4.-The manometer-compensator unit

Inside diameter of manometer arms, $9 \pm 1 \mathrm{~mm}$.

Inside diameter of capillary $U$ connecting manometer arms,

1.5 to $2 \mathrm{~mm}$.
Total length of manometer from $r$ to bottom of capillary $U$, $100 \pm 10 \mathrm{~mm}$.

Length of compensator arm of manometer (left arm) $50 \pm 5 \mathrm{~mm}$. Diameter of compensator below manometer =diameter of the burette. the manometer, as shown in the drawing. Mercury is used as the manometer fluid. When the mercury meniscus rises to touch the point of the contact $(n)$ an electric circuit, 
including a miniature lamp, is closed. The flash of the lamp indicates the balance point. The balance is always obtained by allowing the mercury to flow upward toward the platinum point-never the reverse. The mercury in this arm of the manometer adjacent to the compensator is not in contact with stopcock lubricant and will remain clean for considerable periods. A 3-volt battery supplies the power and a $0.5 \mu \mathrm{f}$ condenser is placed across the leads to prevent arcing. Under these conditions the platinum contact will not foul. The very slow formation of a platinum amalgam makes it necessary to remove the point for cleaning once or twice a year. To do this it is only necessary to remove the supporting sleeve $A$. (A tungsten contact was tried and found altogether unreliable.) A manometer of small bore, such as the type in common use, will cause appreciable error in the pressure adjustment and consequently in the measurement of the gas volumes. Any significant capillary error has been avoided by making the manometer arms from tubing of 9 to $10 \mathrm{~mm}$. inside diameter. The upward flow of the mercury toward the contact point is at a uniform and very slow rate. This is accomplished by a device to be described in the following section.

Referring again to Figure 4, it will be seen that the sleeve $A$ is ground onto a tapered outlet of the compensator dome. Rotation of the sleeve $90^{\circ}$ clockwise from the position shown will connect the compensator to the atmosphere. The sleeve then serves the double purpose of supporting the platinum point, making this easily removable for cleaning, and replacing the stopcock usually attached to the compensator. The glass buttons or hooks $(p)$ provide means of attaching light coiled springs which hold the ground surfaces securely together. These will not be necessary if care is taken never to build up excess pressure within the compensator.

The manometer arm which is to be connected to the burette and distributor terminates at $(d)$ in a capillary cut from the same piece of tubing as $(d)$ of Figure 1 , to which it is joined by a rubber sleeve. The ends of both of these tubes are ground flat and slightly bevelled at the outer rim.

The manometer is sealed into the compensator through the ring seal (r). The dome of the compensator is slightly enlarged to permit the glass blower sufficient latitude. The compensator is drawn off to a smaller diameter somewhat below the lower end of the manometer.

The detail of construction of the bottom of the compensator is also shown in Figure 4. The compensator terminates in the drawn out glass rod $(s)$ to which is cemented the metal sleeve $(t)$. This sleeve is threaded on the outside, and the spring $(u)$ is screwed into this threaded part. These metal parts are chromium plated. $J$ represents a portion of the lower end of the water jacket, which terminates here in a constricted tube $(v)$. The spring fits snugly within this tube and rests upon the constriction. This supports a part of the weight of the compensator and prevents it from swaying within the water jacket. The remainder of the weight of the combined manometer and compensator is supported by the buoyant force exerted by the water within the jacket.

The manometer and compensator may be blown separately. This arrangement was used by Mr. Isedig and is shown in Figure 5 . The platinum contact point $(n)$ is cemented into the manometer as shown. 
This could be improved by substituting a ground sleeve at this point and eliminating the stopcock. This construction is more rasily achieved in the hands of the amateur glass blower, and is illustrated for this reason. It is more fragile than the combined unit, and ordinarily can not be removed from the water jacket without disconnecting other parts of the apparatus. However, it is a distinct improvement over the manometer usually placed outside of the water jacket.

\section{THE PRESSURE CONTROL}

In order to transfer gas from one part of the apparatus to another and to balance the manometer, some method of pressure control is necessary. This usually consists of a vertical movement of the
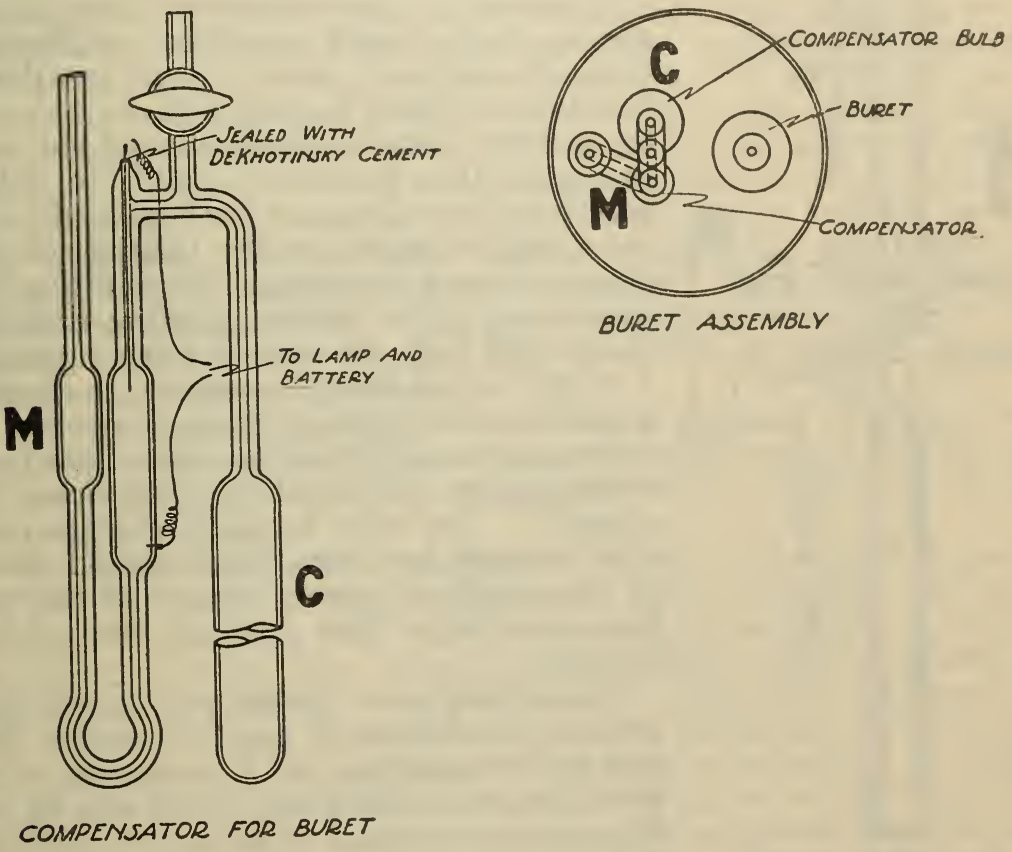

FIGURE 5.-Manometer and compensator as separate units (Ledig)

The assembly within the water jacket is also shown.

leveling bulb which supplies the confining fluid to the burette, and this adjustment is ordinarily made by raising and lowering this reservoir by hand or by some gear system. The latter is cumbersome, and the former both awkward and inaccurate.

Many years' use of the following method has shown it to be simple and accurate. Four rings are fixed to the frame supporting the apparatus. When the leveling bulb is placed on the uppermost of these rings and the burette opened to the atmosphere, mercury from the bulb will completely fill the burette. When the bulb is placed on the lowest ring and the burette opened to the atmosphere, the mercury within the burette will fall to a level a little below the $100 \mathrm{ml}$ mark. 
The remaining two rings are fixed at equal distances between the first two. Mercury may then be introduced or withdrawn from the burette by placing the lereling bulb on the proper ring. The pressure control is obtained by regulating the rate of flow of mercury into and out of the burette. This is accomplished by interposing a

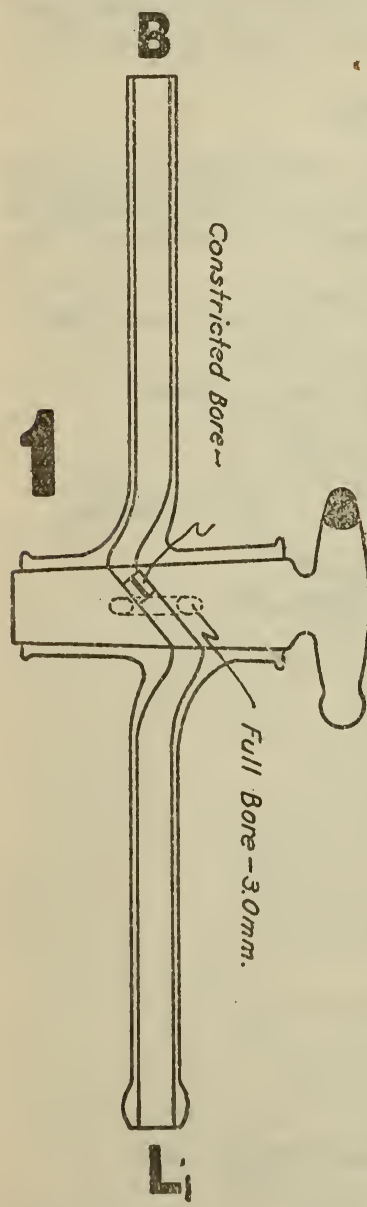

FIgURe 6.-The control stopcock

The stopcock connects to the burette at $B$ and to the levelling bulb at $L_{1}$. Iength of barrel, 40 to $43 \mathrm{~mm}$. Diameter of key at center, $14 \mathrm{~mm}$. The constriction is 2 to $3 \mathrm{~mm}$ in length and will pass a wire $0.125 \mathrm{~mm}$ in diameter, but will not pass a wire $0.15 \mathrm{~mm}$ in diameter. pipettes. It is possible to bring the reagents within the pipettes to etched marks on the capillary exits without danger of drawing reagent into the distributor. For difficult combustions, such as those

- Described in detail in a note, A Simple Control Stopcock for Gas Analysis Apparatus, by Martin Shepherd, B. S. Jour. Research 4, p. 23 (RP130); 1930.

special control stopcock ${ }^{6}$ between the burette and the mercury reservoir. The stopcock is illustrated in Figure 6 . The key of this cock has two bores, one of which is provided with the fine constriction shown. Rough adjustments are made through the large bore, following which a $90^{\circ}$ turn of the key admits an extremely slow flow of mercury to the burette.

In balancing the manometer the mercury can be quickly raised to within a millimeter from the contact point. The constricted bore is then opened to complete the balance, the mercury rising so slowly toward the contact point that the eye is unable to determine when actual contact has been made until the circuit is closed and the lighting of the miniature lamp reveals it. By selecting the proper one of the four supporting rings for the leveling bulb the operator can maintain a roughly equal head of mercury, so causing a fairly uniform rate of flow of mercury in the manometer. When the contact has been made another $90^{\circ}$ turn of the key closes the stopcock. The time lag in closing the cock after contact has been made should result in no significant error, because of the uniform and very slow rate of flow of the mercury.

The control cock is also used to regulate pressures and rates of gas flow within the rest of the apparatus. It is necessary to displace the gas confined within the arm of the manometer connected to the burette and the distributor before passage to any of the pipettes, thus eliminating the errors which will otherwise arise from diffusion of gases into the manometer. The thread of mercury in the capillary exit of the manometer may be safely raised to the bore of the connecting stopcock ( 4 of fig. 1) by using the constricted bore of the control cock. There is thus no danger of emptying the mercury from the manometer into the distributor. The same control is used in displacing gas from the to bring the reagents within the pipettes 
involving acetylene, ethylene, ethane, propane, and heavy hydrocarbons, where thermal decomposition with the deposition of carbon is apt to occur, a very slow rate of flow of the combustible gras into the combustion pipette is necessary, and is readily insured by use of the control cock.

The stopcock can be made in several ways. The glass blower may seal a No. 37 (B. \& S. gage) copper wire into the solid key and along the axis of one bore. The key is then drilled out from opposite sides, leaving an unarilled segment 2 to $3 \mathrm{~nm}$ in thickness just off the center of the key. Nitric acid is used to remove the copper wire from the undrilled portion. A second method is as follows: Draw down a 6 to $7 \mathrm{~mm}$ glass tube so that one end is sealed shut and the outside diameter of the tube fits snugly into the ordinary $3 \mathrm{~mm}$ bore of the stopcock key. Cut or grind off the end of this tube, beginning at the point where the tube first opens into a fine capillary, and continue until the capillary will permit the passage of a No. 38 (B. \& S. gage) wire, but will not pass a No. 36 wire. (The gage wire is inserted from the large end of the tube.) The constriction is now of the proper size, and a section of 2 to $3 \mathrm{~mm}$ in length should be cut from the tube at this point. This section is cemented within the ordinary bore of the stopcock. DeKhotinsky cement is suitable, and should be applied to the outside of the section, which is then slipped into the bore of the stopcock key. The key is then placed in an electric oren, heated slowly to $130^{\circ} \mathrm{C}$., and then allowed to slowly cool to room temperature within the oven.

The fine constriction must be set within the bore of the key and away from the outside surface as shown in the drawing. When this is done no trouble results from plugging of the constriction by the stopcock lubricant.

It is important that the position of the key of all control stopcocks should be made uniform. Experience has shown that the most desirable orientation is as follows: One end of the handle of the key should be marked with colored glass, a bright paint or a knob as shown on the drawing. If the stopcock is attached to the burette in the position shown, the indicating end of the handle should point upward when the key is turned to open the constriction. It should point outward (toward the reader) when the key is turned to open the full bore, and inward (away from the reader) when the key is turned to close the stopcock. If these directions are observed, the operator will soon accustom himself to these positions, and will not be at a loss when operating another apparatus with similar control.

\section{THE WATER JACKET}

The water jacket of the usual gas analysis apparatus has a large rubber stopper at the lower end. The burette projects through a hole in this stopper, and the lower end of the compensator may or may not be supported by a cup in the stopper. 'This stopper has seemed to be an inconvenient necessity. The stopper may leak, drop out of place, split the jacket if thrust in too tightly, or stick to the jacket so that its removal therefrom is a questionable operation. Two means of eliminating the troublesome stopper are offered. Both are illustrated in Figure 7. 
The first of these consists of a molded rubber sleeve $(x)$, made from sulphur-free rubber. This fits over the outlet $(w)$ of the water jacket. The burette $B$ slips loosely through the outlet and is then gripped by the smaller bore of the rubber sleeve. The control stopcock $(1)$ is also secured in place within the smaller bore of the sleeve, so that its end butts against the lower end of the burette. This eliminates all of the undesirable features of the large stopper with the exception of the tendency of the rubber to stick to the glass. If this occurs it

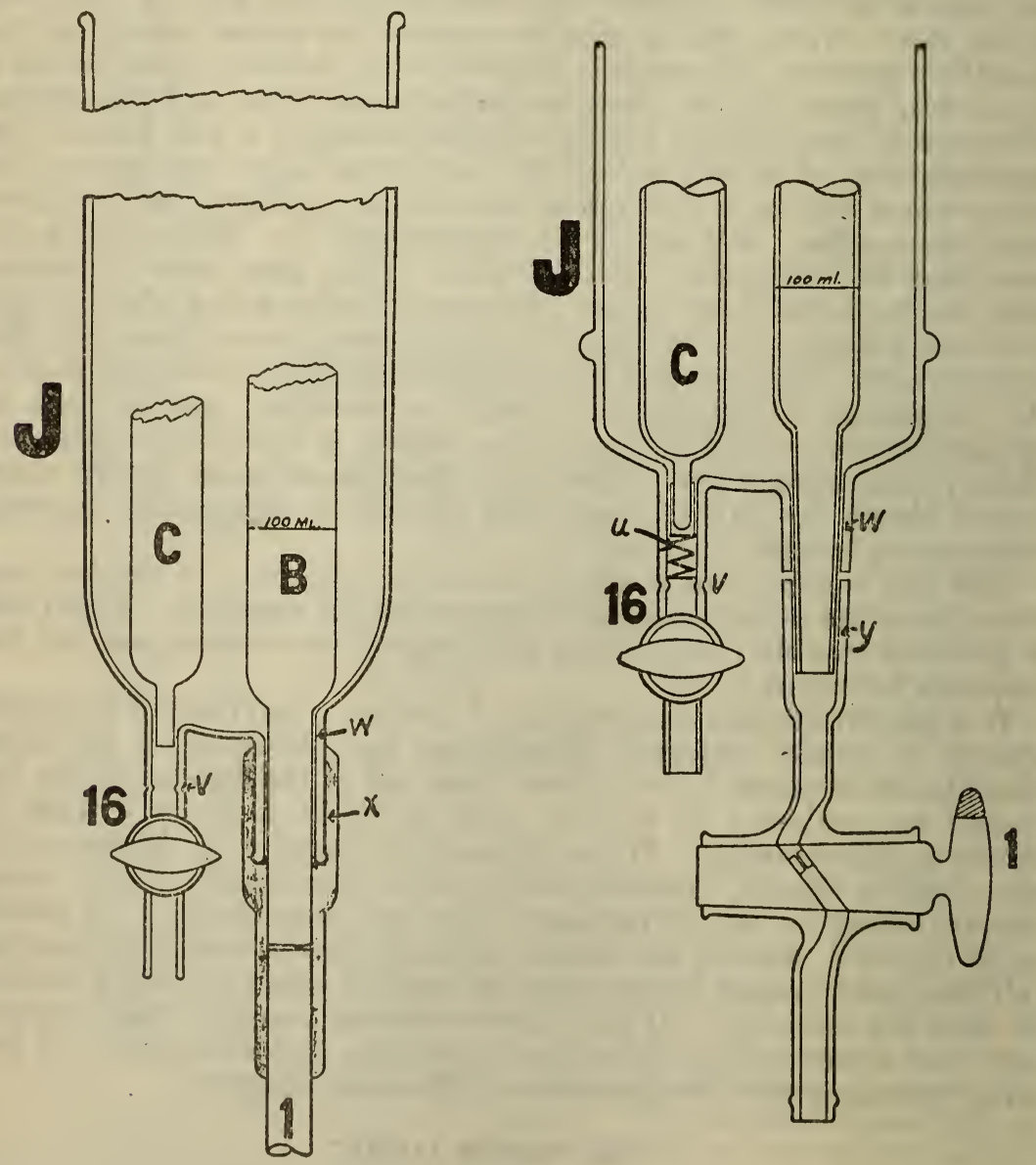

Figure 7.-The water jacket

Two methods of assembling the burette and control stopcock are shown. Diameter of jacket, 70 to $75 \mathrm{~mm}$.

will, of course, be necessary to cut the sleeve to remove it and subsequently replace it with a new one.

The second method involves a slightly more difficult construction, but eliminates the two objections of the possibility of the rubber sleeve sticking to the glass and the necessity of eventually replacing it. The outlet of the water jacket $(w)$ is tapered but not ground. The lower end of the burette is tapered to fit loosely inside of the outlet. 
The upper lead from the control stopcock is flared $(y)$ to looscly fit the lower portion of the tapered burette. These parts are cemented together by warming gently and applying DeKhotinsky cement until it flows smoothly around the spaces between $(w),(y)$, and the tapered burette end.

It will, of course, be necessary to specify diameters in ordering replacement parts. The apparatus maker should standardize theso parts as well as other relevant dimensions throughout the apparatus.

There is some advantage in sealing cock 1 directly to the burette. This, of course, makes it necessary to cut ofi the stopcock if the burette is to be removed from the jacket. Since the burette is easily cleaned in place it will ordinarily not have to be removed. If this should become necessary, the glass blowing involved is not beyond the ability of the average amateur.

The water jacket is best made from Pyrex tubing. The outlet $(v)$ which is constricted to support the compensator as previously noted, terminates in stopcock 16 which may be used to drain the jacket or admit air to stir the water.

\section{THE DISTRIBUTOR}

The distributor or manifold connecting the burette to the various pipettes may be filled with a confining fluid or an inert gas. A mercury-filled distributor possesses the advantage of eliminating

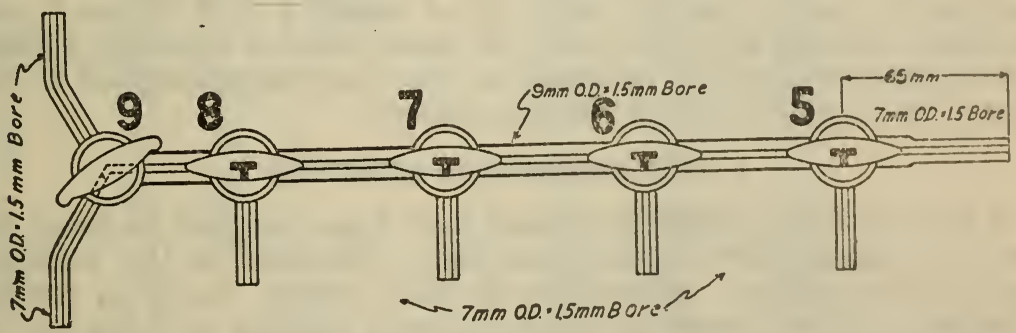

FIGURE 8. -The distributor

Tolerance on outside diameter of $7 \mathrm{~mm}$ capillary tubing, $\pm 0.2 \mathrm{~mm}$.

Tolerance on bore of all capillary tubing, $\pm 0.1 \mathrm{~mm}$.

Length of barrels of all stopcocks, 33 to $35 \mathrm{~mm}$.

Diameter of keys of stopcocks, at center, 12.5 to $13 \mathrm{~mm}$

Diameter of klightly bereled at the outer rim.

errors arising from diffusion into capillary dead spaces, but such a system may trap gas unless carefully made, and, in addition, requires a relatively complicated apparatus and more skill to operate. Furthermore, it is possible to eliminate errors associated with the dead capillary space of a gas-filled train.

The usual nitrogen filled distributor has been selected, since it is better adapted to the work expected from this type of apparatus. This is shown in Figure 8. A series of tee stopcocks (5 to 8, inclusive) permits the gas stream from the burette to be confined to only that portion of the distributor which leads directly to the pipette into which the gas is to be introduced. This eliminates to a large extent capillary dead spaces. A $120^{\circ}$ cock (9) placed at the end of the distributor permits connection to the atmosphere, an nuxiliary source of nitrogen, or acidulated water if the distributor is to be 
flushed in situ. The latter technique is somewhat objectionable. It becomes necessary only when a reagent is accidentally discharged into the distributor, a catastrophe which may easily be avoided when the pressure control already described is used. And in the event the operator inadvertently brings this calamity upon himself, the distributor should be dismounted and properly cleaned. Flushing in situ is at best an expedient to be used only in special cases. An alkaline reagent will ruin the grinding of the distributor stopcocks and should be washed out immediately. It is also obvious that even traces of a reagent in the distributor will spoil an analysis.

The distributor may have as many tee stopcocks as the type of analysis demands. The one illustrated in Figure 8 provides connections to pipettes containing solutions of potassium hydroxide and alkaline pyrogallol, a combustion pipette, and a fourth pipette which may be used for an additional reagent or the storage of nitrogen. As will be pointed out later on, this simple combination can be used to analyze a large number of gas mixtures.

The bores of the stopcocks and distributor are important. These are made as small as possible without introducing the danger of periodically plugging the bores with lubricant. The outside diameters are also important, and it will be noted that the distributor is stronger than the usual type. The dimensional tolerances given in Figures 8 and 1 may seem severe, but they have resulted from long and not always happy experience. The right-hand exit of the distributor connects to the outlet $(c)$ of stopcock 4 of Figure 1, and preferably should be made from the same piece of capillary tubing, ground flat and slightly bevelled, as was previously specified in the case of the capillary exit of the manometer.

\section{THE ABSORPTION PIPETTES}

A number of gas analysis pipettes have been designed to bring the gas and reagent into intimate contact. Pipettes of the bubbling type possess distinct advantages in this respect, being in general superior to those depending upon an inner packing of some sort to provide contact surface. The ordinary bubbling pipette was first designed by Hankus in 1899.7 It appears at present in various modifications and under various names.

A simple form of this pipette is used with the present apparatus to absorb carbon dioxide. The absorption of this gas by a solution of potassium hydroxide is very rapid, and a more complicated form of pipette is not warranted. The pipette is shown in Figure $9\left(P_{2}\right)$. The tip of the gas inlet has been lipped to aid the emerging gas bubble in breaking away from the glass exit tube. This results in the formation of somewhat smaller bubbles. In withdrawing the gas from the pipette, the reagent is brought to etched marks shown on the capillary tubes.

The simple bubbling pipette is not as satisfactory for the absorption of oxygen. The reagent used for the absorption of oxygen is an alkaline pyrogallol solution similar to the formula recommended by Anderson. ${ }^{8}$ Other reagents, some of them more rapid in their rate of reaction, have been tried, but these have proved to be unsatisfactory. For the quantitative removal of oxygen the pyrogallol

7 Hankus, E. F., Osterr. Chem. Ztg., 47, p. 81; 1899. Also J. Gasbel., 49, p. 367; 1906.

8 Anderson, R. P., Ind. Eng. Chem., 7, p. 588; 1915. 
solution seems to be the most suitable. The reaction is comparatively slow, and it requires about 10 passages through the plain bubbling pipette to remove oxygen from air. A more efficient pipette is therefore needed for this purpose.

Among the modifications of the plain bubbling pipette is one adapted from the Friedrichs gas washing bottle. This is described by L. M. Dennis, ${ }^{9}$ who reports the complete removal of oxygen from air after three passages into alkaline pyrogallol contained in this form of
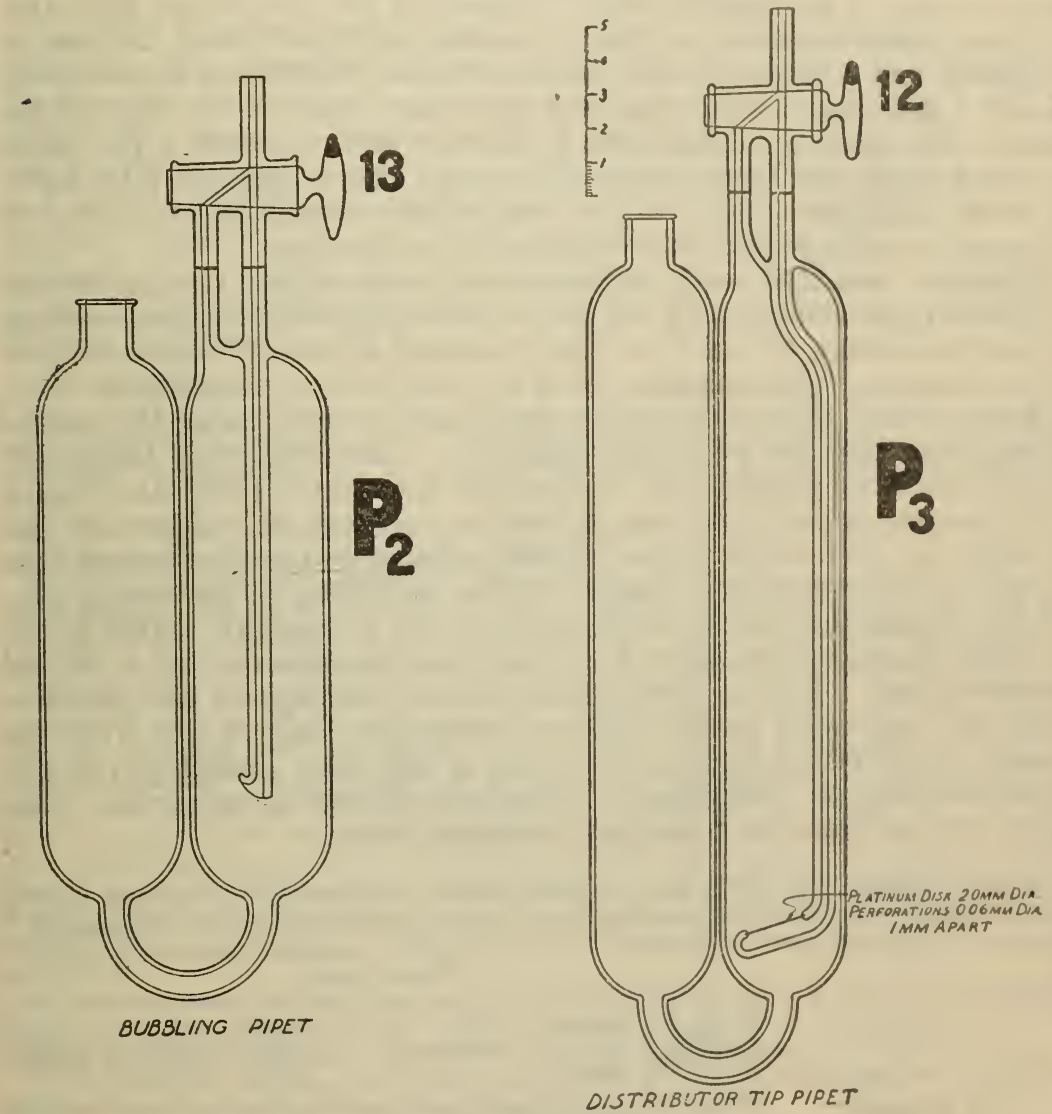

FIGURE 9.-The absorption pipettes

The plain bubbling pipette for less difficult absorptions is shown on the left, and the "distributor" pipette for difficult ute capillary outlet should be ground flat . Diameter of key af stopcock, 12.5 to $13 \mathrm{~mm}$ at center. Capillary bores, 2 to $2.5 \mathrm{~mm}$.

pipette. Dennis also reports a similar efficiency for the spiral pipetto designed by Nowicki ${ }^{10}$ and improved by Heinz. ${ }^{11}$ Either of these two pipettes is satisfactory for the removal of oxygen, provided it is properly constructed. Some faults likely to occur in the construction are pointed out in a previous publication. ${ }^{12}$

9 Dennis, L. M., Gas Analysis, p. 81 (fig 47), The Macmillan Co., New York; 1913

10 Nowicki, Osterr. Z., Berg Hüttenw., 53, p. 337; 1905

11 Heinz, J. Gasbel., p. 49, 367; 1908 .

12 Shepherd, Martin, A Gas Analysis Pipette for Difficult A bsorptions, B. S. Jour. Research, 4, 747; 1930. 
In this same note the development of a very efficient pipette is reported. The development was initiated when the Jena glass sintered filters were first introduced. The gas inlet tube of an ordinary bubbling pipette was tipped with a coarse Jena filter. The gas stream was finely divided and fairly rapid absorption resulted; but the filter plate trapped a measureable amount of gas. Accordingly, a thin platinum plate perforated with numerous small holes was substituted. Such a plate is best obtained from one of the companies engaged in manufacturing spinnerets for the rayon industry. A plate found suitable for this purpose is $0.05 \mathrm{~mm}$ thick, $20 \mathrm{~mm}$ in diameter, and perforated with holes $0.06 \mathrm{~mm} \pm 0.005 \mathrm{~mm}$ in diameter, spaced $1 \mathrm{~mm}$ apart, and extending to within $2 \mathrm{~mm}$ of the edge of the plate. The burrs resulting from drilling are not removed. The plate is sealed (with the burrs upward) into the end of the gas inlet tube, as shown in Figure $9\left(P_{3}\right)$. The end is dish-shaped and is placed at an angle in order to prevent trapping the return gas.

There are over 200 small orifices in such a plate, and the gas issuing is broken up into many fine bubbles, which apparently do not coalesce. A froth consisting of small bubbles separated by liquid films is formed at the surface of the reagent. This layer of froth is about $2 \mathrm{~cm}$ deep, and some absorption must take place here as well as in the actual passage through the pyrogallol solution. The froth very obligingly disappears when the gas flow through the perforated plate has ceased.

A pressure of about $30 \mathrm{~mm}$ of mercury is required to force the gas through the perforated plate. A $100 \mathrm{ml}$ sample may be passed into the pipette in about 20 seconds. At the beginning of the absorption, the gas passes through approximately $19 \mathrm{~cm}$ of reagent. This depth of liquid decreases to about $6 \mathrm{~cm}$ with the introduction of a $100 \mathrm{ml}$ sample of gas. In the Dennis-Friedrichs spiral pipette the effective depth of reagent is nearly $125 \mathrm{~cm}$, decreasing only $5 \mathrm{~cm}$ with the passage of a $100 \mathrm{ml}$ sample. In spite of this fact, absorption in the platinum plate or "distributor" pipette is slightly more rapid. This may be seen from the following tabulated data:

TABLE 1.-Percentage of the total oxygen content of air which is removed during each passage into various types of bubbling pipettes containing alkaline pyrogallol

\begin{tabular}{|c|c|c|c|c|c|c|c|}
\hline \multirow{5}{*}{ No. of passages } & \multicolumn{7}{|c|}{ Type of pipette } \\
\hline & $\begin{array}{l}\text { Plain } \\
\text { bubbling }\end{array}$ & $\begin{array}{l}\text { Dennis- } \\
\text { Fried- } \\
\text { richs }\end{array}$ & \multicolumn{2}{|c|}{ Distributor } & $\begin{array}{c}\text { United } \\
\text { States } \\
\text { Steel } \\
\text { Co.1 }\end{array}$ & $\begin{array}{l}\text { Dennis- } \\
\text { Fried- } \\
\text { richs 1 }\end{array}$ & $\begin{array}{l}\text { Nowicki- } \\
\text { Heinz }\end{array}$ \\
\hline & \multicolumn{7}{|c|}{ Time consumed for each passoge (seconds) } \\
\hline & 20 & 45 & 20 & 45 & 60 & 60 & 60 \\
\hline & \multicolumn{7}{|c|}{ Oxygen removed } \\
\hline & $\begin{array}{r}\text { Per cent } \\
40.2 \\
63.8 \\
76.8 \\
86.5 \\
91.8\end{array}$ & $\begin{array}{r}\text { Per cent } \\
93.6 \\
99.4 \\
100.0\end{array}$ & $\begin{array}{r}\text { Per cent } \\
94.9 \\
99.8 \\
100.0\end{array}$ & $\begin{array}{r}\text { Pcr cent } \\
97.1 \\
100.0\end{array}$ & $\begin{array}{r}\text { Per cent } \\
43.1 \\
68.0 \\
82.3 \\
90.0 \\
94.8\end{array}$ & \begin{tabular}{|} 
Per cent \\
89.0 \\
97.6 \\
100.0
\end{tabular} & $\begin{array}{r}\text { Per cent } \\
98.6 \\
99.5 \\
100.0 \\
\end{array}$ \\
\hline & $\begin{array}{r}94.8 \\
97.2 \\
98.6 \\
99.6 \\
100.0\end{array}$ & & & & $\begin{array}{r}97.7 \\
98.6 \\
100.0\end{array}$ & & . \\
\hline
\end{tabular}

1 Results obtained by L. M. Dennis, Gas Analysis, p. 82, The Macmillan Co., New York, 1913.

a plain bubbling pipette of slightly greater length than the one shown in fig. 9 . 
The absorption pipettes of the apparatus are, therefore, not alike. Each pipette is designed for its specific purpose. It would be a needless expense to use the distributor pipette for the absorption of carbon dioxide and a waste of time to use the plain pipette for the absorption of oxygen. The difference in length of the pipettes is easily provided for in the supporting frame.

\section{THE COMBUSTION PIPETTE}

- In 1920 Weaver and Ledig ${ }^{13}$ described a new combustion pipette which possessed marked advantages and eliminated the unsatisfactory features of the usual type in general use at that time and, it must be added, at present. This usual type, originally known as the Dennis and Hopkins pipette and appearing now under various names, has two leads brought into the bottom of the pipette through a rubber stopper, whence they project through the confining fluid to near the dome of the pipette, there connecting to the platinum combustion spiral. The unsatisfactory features of this pipette are listed by Weaver and Ledig as follows:

1. It is difficult to make the stopper at the bottom of the pipette and the connections through it perfectly tight. The leakage of mercury is easily detected, but the pipette may be tight to mercury and allow air to leak in when its contents are under reduced pressure, and such a leak is likely to be overlooked for a long time.

2. The weight of the mercury in such a pipette produces a serious danger of its forcing out the stopper and spilling the mercury.

3. In order to insulate the leads it is necessary to inclose one or both of them in glass tubes. The platinum wire is usually sealed through these tubes and the connection with the lead made inside the glass tube. This is a rather difficult form of construction and one hard to repair. The point at which the wire is sealed through the insulating tube is the most likely to crack in the whole apparatus, and such cracking is likely to cause an undetected leak. If the leads pass through the glass and the active wire is crimped on, as is sometimes done, the junction usually has the highest resistance of any part of the circuit and is the first to fail in use. A solder can not, of course, be used in the presence of mercury. As the apparatus is frequently constructed, sufficient relative motion between the leads to distort or even break the platinum wire is possible. (It may be added that in case the platinum wire is supported on a ceramic body, uneven heating is apt to result and only a portion of the wire may be heated sufficiently to cause combustion to take place. Also, gas may be trapped or absorbed by the ceramic support.)

4. The necessity of bringing two leads and a tube for the flow of the confining fluid out at the bottom of the pipette makes it difficult to support so heavy a weight without mounting it on a more or less bulky supporting frame.

5. In order to replace the platinum wire it is always necessary to drain the pipette completely and usually to disconnect it entirely.

The pipette designed by Weaver and Ledig overcomes these difficulties. It is shown in Figure 10. It is made of Pyrex glass, has $\Omega$ volume of approximately $150 \mathrm{ml}$ and is used with mercury as a confining fluid. The platinum combustion coil is strung through two side arms which are tapered slightly at the ends. Weaver and Ledig fitted soft glass caps to the outside of this taper. Through the end of each cap a heavy platinum wire was sealed. Steel caps have now been substituted $(Z, Z)$ terminating in ordinary binding posts. 'These caps are not susceptible to the breakage which may occur on warming or mishandling the soft glass caps, and afford a nice means of securing the power leads to the pipette.

13 E. R. Weaver and P. G. Ledig, New Forms of Combustion Apparatus for Use in Gas Analysls, J. Ind. Eng. Chem., 12, p. 368; 1920. 
To place the combustion coil within the pipette and secure it is a perfectly simple operation, requiring but a few minutes time. About 20 turns of the platinum wire are wound snugly around a stiff wire of approximately $1.5 \mathrm{~mm}$ diameter. About $8 \mathrm{~cm}$ of wire is left at each end of the coil. The coil is removed from the form upon which it was

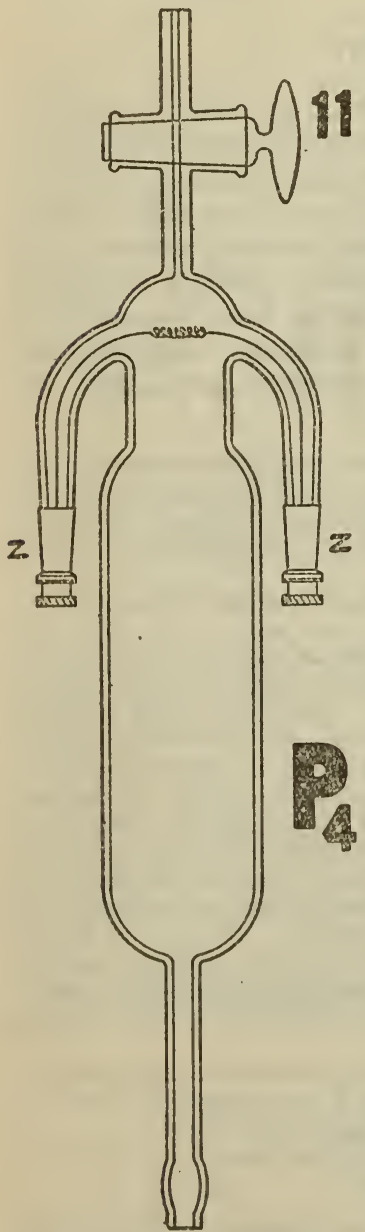

TrGURE 10.-The combustion pipette

Capacity, $150 \mathrm{ml}$.

Outside diameter of largo section, $38 \mathrm{~mm}$.

Outside diameter of top section, $26 \mathrm{~mm}$.

Made from Pyrox glass. wound, and one of the projecting wires is bent slightly. The whole may now be easily strung through the side arms, leaving the uncoiled ends projecting therefrom. These are grasped between two fingers of each hand and the coil is stretched until it just extends across the dome of the pipette. The ends projecting from the side arms are now bent sharply upward around these arms. This holds the coil in place until the caps are slipped over the tapered ends of the side arms. The caps are cemented in place with DeKhotinsky cement. If it becomes necessary to replace the coil, one has simply to warm the caps, remove them, thread through a new coil, replace the caps, and again warm them gently to secure the DeKhotinsky seal.

About $20 \mathrm{~cm}$ of wire is required to make the combustion coil. A 90 per cent platinum10 per cent iridium alloy is used. The diameter of the wire should be 0.16 to $0.17 \mathrm{~mm}$. Wire of this size will make a coil which supports itself at white heat, and the current required to heat it is not excessive. (About 2 to 2.3 amperes. The ordinary 110 -volt circuit is used in connection with a tubular rheostat rated at $120 \mathrm{ohms}, 2.2$ amperes.)

When the pipette is first filled, mercury falls into the side arms and makes the electric contact between the caps and the combustion coil. These arms are of sufficient length to dissipate the heat from the dome of the pipette, so that the cement is not softened.

This pipette has been found so much more satisfactory than the usual type that the latter has been entirely abandoned in our laboratories.

No provision has been made for connecting a fractional combustion tube. When the apparatus is made, additional tee cocks placed one on each side of the cock which connects the combustion pipette to the distributor (cock $\gamma$ of fig. 8) with the outlets pointing upward, will accommodate such a tube. Its use is left to the judgment of the analyst. 


\section{THE SAMPLING PIPETTE}

The sampling pipette used is similar to the standard typo constructed with two so-called " 3 -way" stopcocks, as shown in Figure 11. The convenience of this arrangement is at once apparent. 'The sampling line may be flushed with the sample itself or with a confining fluid when the sample is taken. Similarly, the same operations may be performed after the pipette is connected to the burette. And, finally, air may be displaced from the tubing connecting the leveling bulb containing the displacing fluid. The identity of the sample is thus preserved at all times and with no extra trouble.

The capillary exits at the top and bottom are of different bores, and are designed to accommodate the flow of gas (top) and confining fluid (bottom). The capacity of the pipette is large enough to provide three samples for analysis.

\section{METHOD OF SECURING CONNECTIONS}

The connections between the distributor and the pipettes and burette, and between the burette and manometer, are made with rubber tubing. In view of the fact that the pressures within the apparatus do not differ greatly from atmospheric, this simple method is satisfactory. The rubber connection, however, should be properly secured. A simple and very effective method for doing this is as follows: The ends of the capillary tubes are butted as closely together as possible. The joint is then secured by wrapping a number of turns of heavily waxed dental floss around the rubber tubing above and below the point at which the glass capillaries meet. Each turn is pulled tight and the wax upon the silk floss holds each turn in place until the next one is made. A connection properly made in this manner will not leak under the ordinary pressure conditions existing during the analysis. The bore of the rubber tubing should be a little, but not much, smaller than the outside diameter of the glass, so that the rubber will be under compression beneath the wrapping and under only slight tension elsewhere.

If a suitable grade of transparent gum tubing is available, its use is to be preferred, largely on account of the desirability of observ-

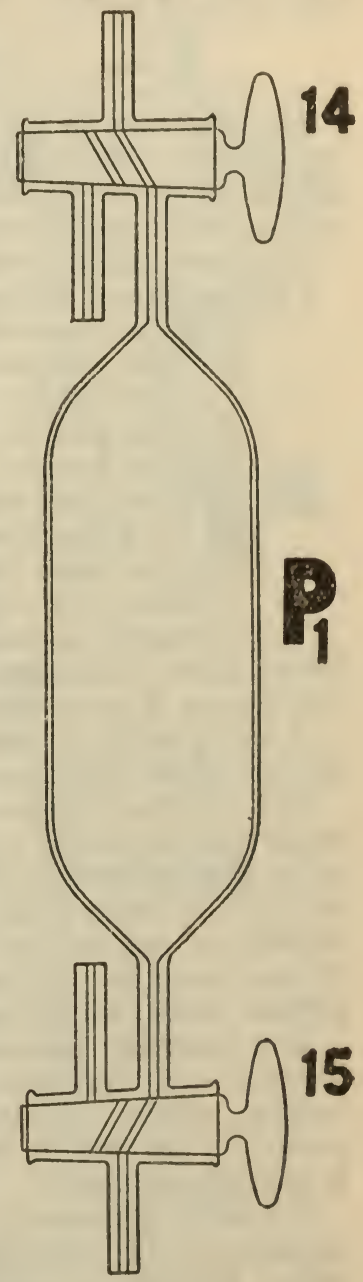

Figure 11.-The sampling pipctte

Capillary tubing of stopeock $14,7 \mathrm{~mm} 0$. d. $x 1.5 \mathrm{mal} i$. d. Tubing of stopcock $15,7 \mathrm{~mm}$ $0, d . x 4 \mathrm{~mm}$ i. d.

Length of bulbed portion, 150 to $155 \mathrm{~mm}$

Over-all length, $290 \mathrm{~nm}$.

Capacity, 2-sample size, 230

ml.
Capacity, 3-samplo size, 330 min. ing the mercury thread in the capillary exit of the manometer when the gas in this arm of the manometer is displaced. The rubber tubing should be replaced frequently enough to keep it in good condition, 
since old rubber tubing is a prolific and frequently unsuspected source of leaks.

Sulphur-free rubber tubing should be used to connect $L_{1}$ to $B, L_{2}$ to $P_{1}$ and $L_{3}$ to $P_{4}$. Nitrometer tubing of reddish-gray rubber, which will not foul mercury, has been found best.

\section{THE ASSEMBLY}

The assembly of the gas analysis unit is shown in Figure 12. For convenience the various parts have been lettered to correspond to the detail drawings which have preceded. The designations of the various parts are classified as follows:

Numbers indicate stopcocks.

Capital letters indicate major parts of the apparatus:

$B$ is the burette.

$C$ is the compensator.

$I$ is the burette illuminator.

$J$ is the burette water jacket.

$L_{1-3}$ are leveling bulbs.

$M$ is the manometer.

$P_{1-5}$ are the pipettes.

$R_{1-7}$ are rings which support the leveling bulbs.

$S$ is the sampling connector.

The electrical apparatus and circuits are not shown in Figure 12. These appear elsewhere in a photograph. The apparatus support is also shown in more detail in this photograph and a drawing.

A brief study of the assembly drawing will afford a preliminary picture of the apparatus as a unit.

The burette is placed at the right so that the manipulation of the important stopcocks $1,2,3$, and 4 and the leveling bulb $L_{1}$, is natu$\mathrm{ral}$ to a right-handed operator. It will be remembered that the leveling bulb is never held in the hand during a pressure adjustment or transfer of gas, so that its manipulation does not interfere with that of the stopcocks. If the operator is left handed, a mirror image of the present model would be more suitable for his use.

The sampling pipette $P_{1}$, which is a nomadic part of the unit, is mounted just outside of the frame proper and to the right of the burette, where a connection is easily made. Its leveling bulb is supported on the ring $R_{5}$, which is mounted on the back of the frame and is open at the side.

For an analysis such as will be described to illustrate the use of the apparatus, the absorption pipettes are arranged in the following order: First is the pipette $P_{2}$ containing potassium hydroxide solution. Next is $P_{3}$ containing alkaline pyrogallol. Following this is the combustion pipette $P_{4}$. And finally the absorption pipette $P_{5}$, which is used as a source of nitrogen for the distributor. This system of pipettes is arranged to correspond to the various steps of the analysis. The combination is reduced to as simple a form as possible for ordinary gas analysis, and may be elaborated to suit special requirements.

The leveling bulb $L_{3}$ connected to the combustion pipette is supported on the rings $R_{6}$ and $R_{7}$, which are open at the side and mounted 


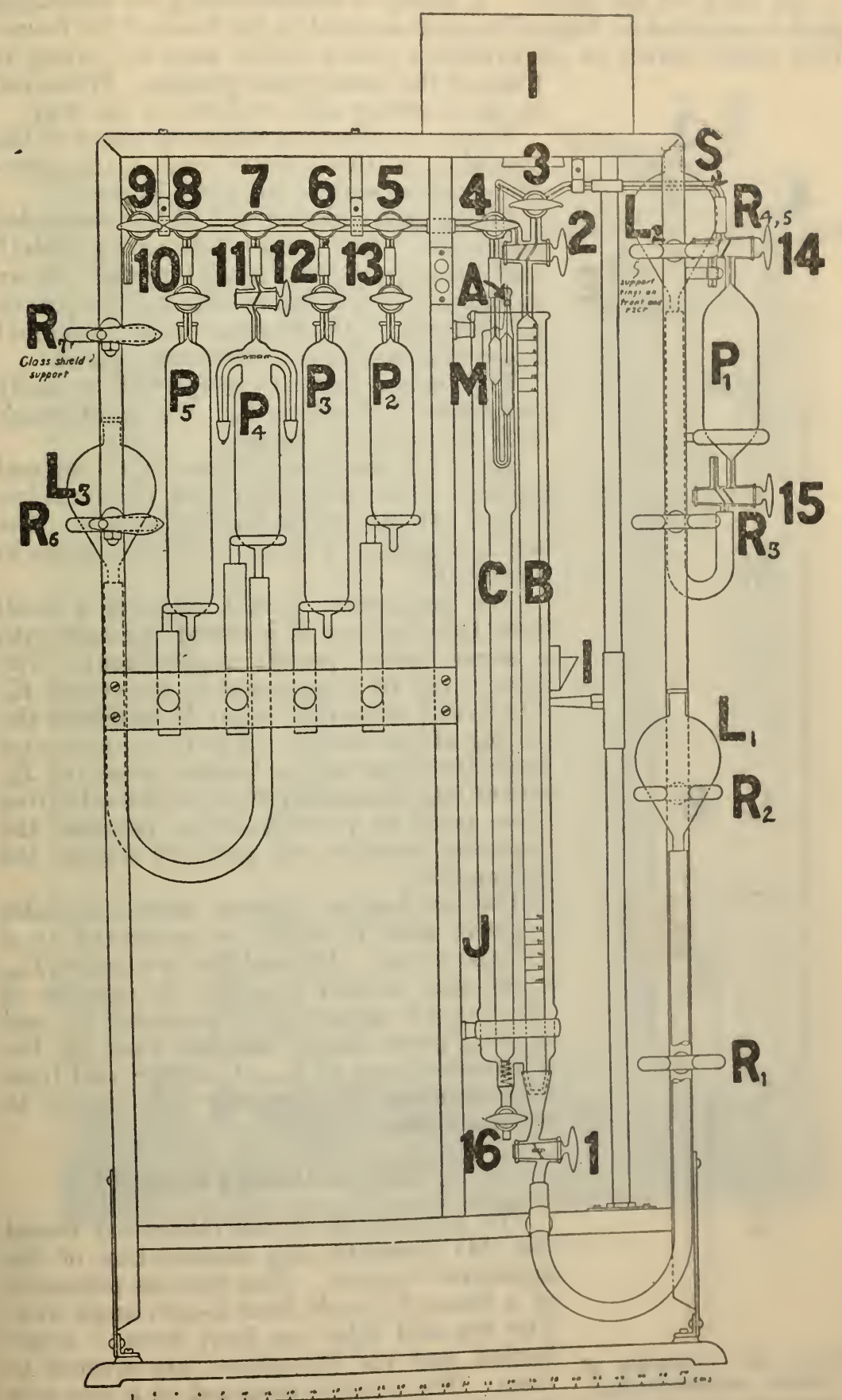

Figure 12.-The assembled apparatus 
at the back of the frame. A shield of nonshattering or laminated glass is mounted on hinged brackets secured to the front of the frame. This shield serves as an explosion guard which may be swung in

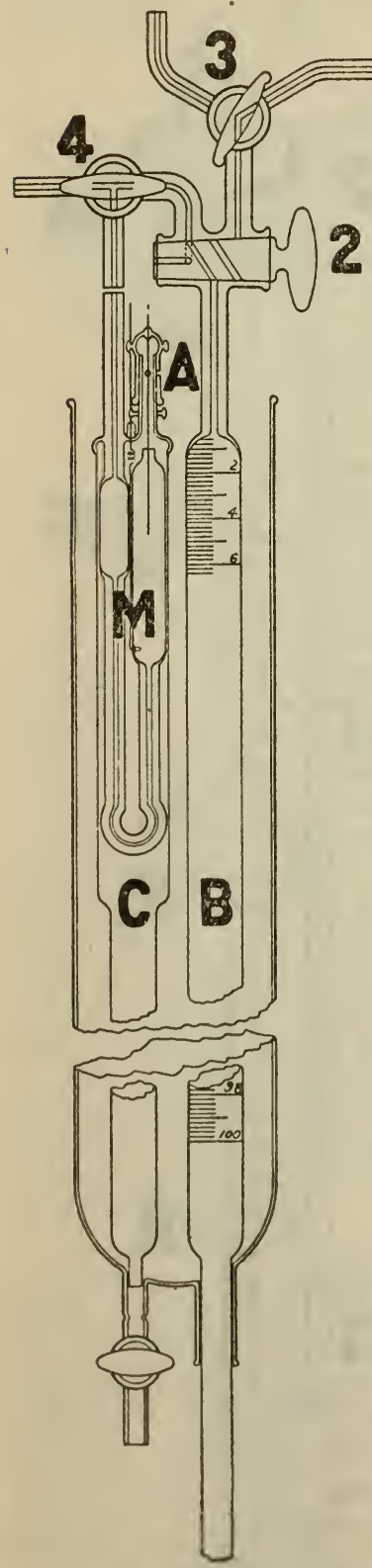

Figure 13.-Assembly of burette, manometer-compensator, and water jacket front of the combustion pipette. When not in use it swings aside and out of the way.

Figure 13 affords a closer scrutiny of the assembly of the burette and manometercompensator within the water jacket.

Figure 14 is a photograph of the assembled apparatus. This is the "laboratory model" and differs from the "special model" shown in Figure 15 only in minor details. The principal difference is that the electrical equipment is not mounted on an instrument panel.

The various parts of the unit will be easily recognized by comparing the photograph with the assembly drawing.

There are two electric circuits, the several parts of which are designated by the letter $E$ (fig. 14) with numerical subscripts. The wiring diagrams of these circuits are given in Figure 16.

The manometer circuit includes a 3-cell flash light battery $E_{5}$ inclosed in a case with a screw cap to permit replacement. The current can be interrupted at the switch $E_{4}$. The 3-volt miniature lamp $E_{2}$ indicates the closing of the circuit. The two manometer leads are connected to binding posts at $E_{1}$, and at $0.5 \mu \mathrm{f}$ condenser $E_{3}$ is connected across these posts to prevent arcing between the platinum contact and mercury within the manometer.

The combustion pipette circuit includes a power inlet $E_{9}$ which is connected to a 110 -volt outlet. Beyond this is a switch $E_{10}$, a $100-$ ohm tubular rheostat $E_{8}$ capable of carrying 2.2 amperes, an ammeter $E_{7}$, and binding posts located at the back of the apparatus frame at $E_{6}$. A flexible cord from these binding posts carries the current to the combustion pipette.

\section{THE APPARATUS SUPPORT}

The photograph of the laboratory model (fig. 14) illustrates the construction of the apparatus support. This consists primarily of a frame $F_{1}$, made from $3 / 4$-inch angle iron. The top and sides are bent from a single section and the crosspieces are riveted to them. The whole is mounted on a cast-iron base $F_{5}$. The crosspieces and gusset plates 
B. S. Journa! of Research, RP266

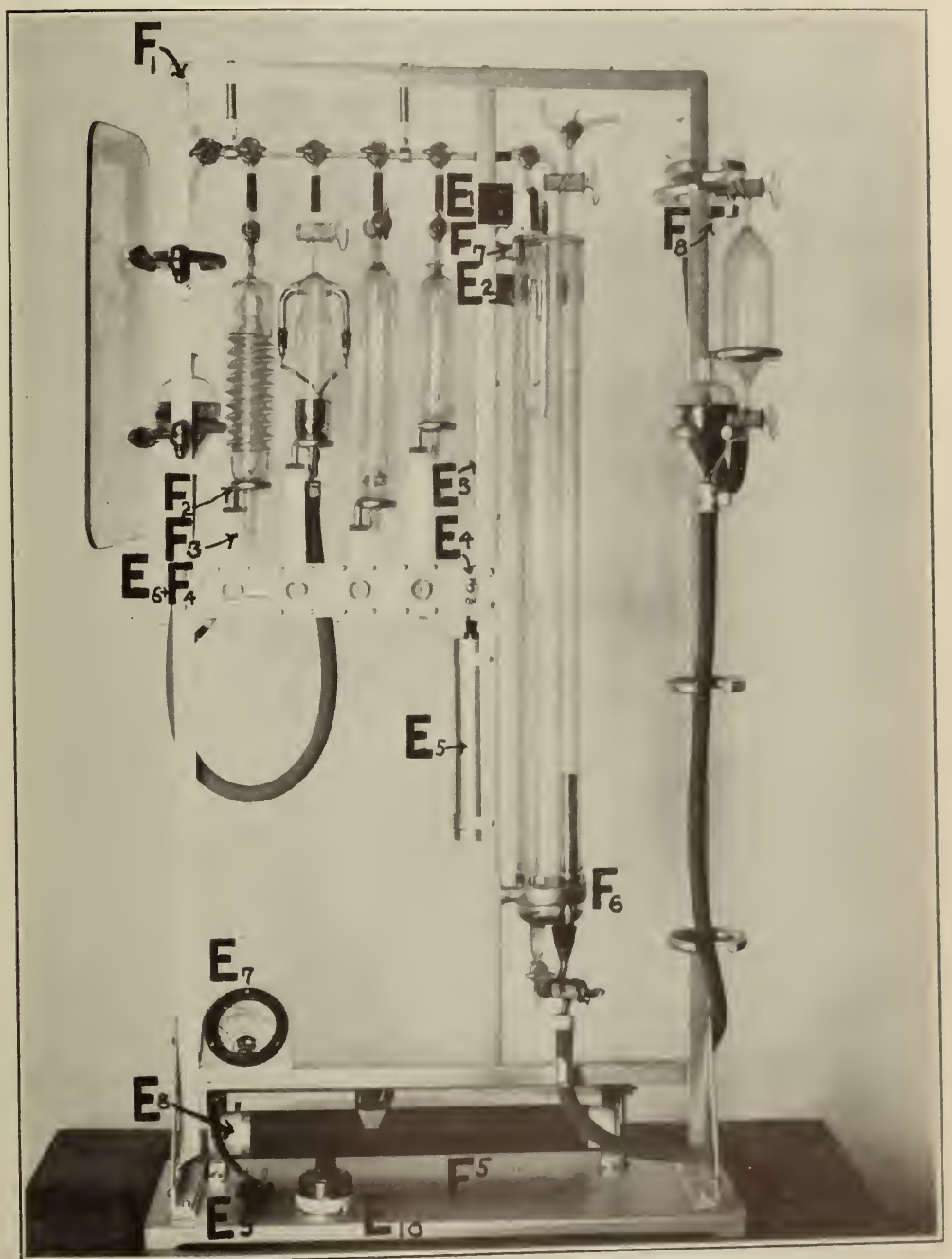

Figure 14.-The luboralory model 


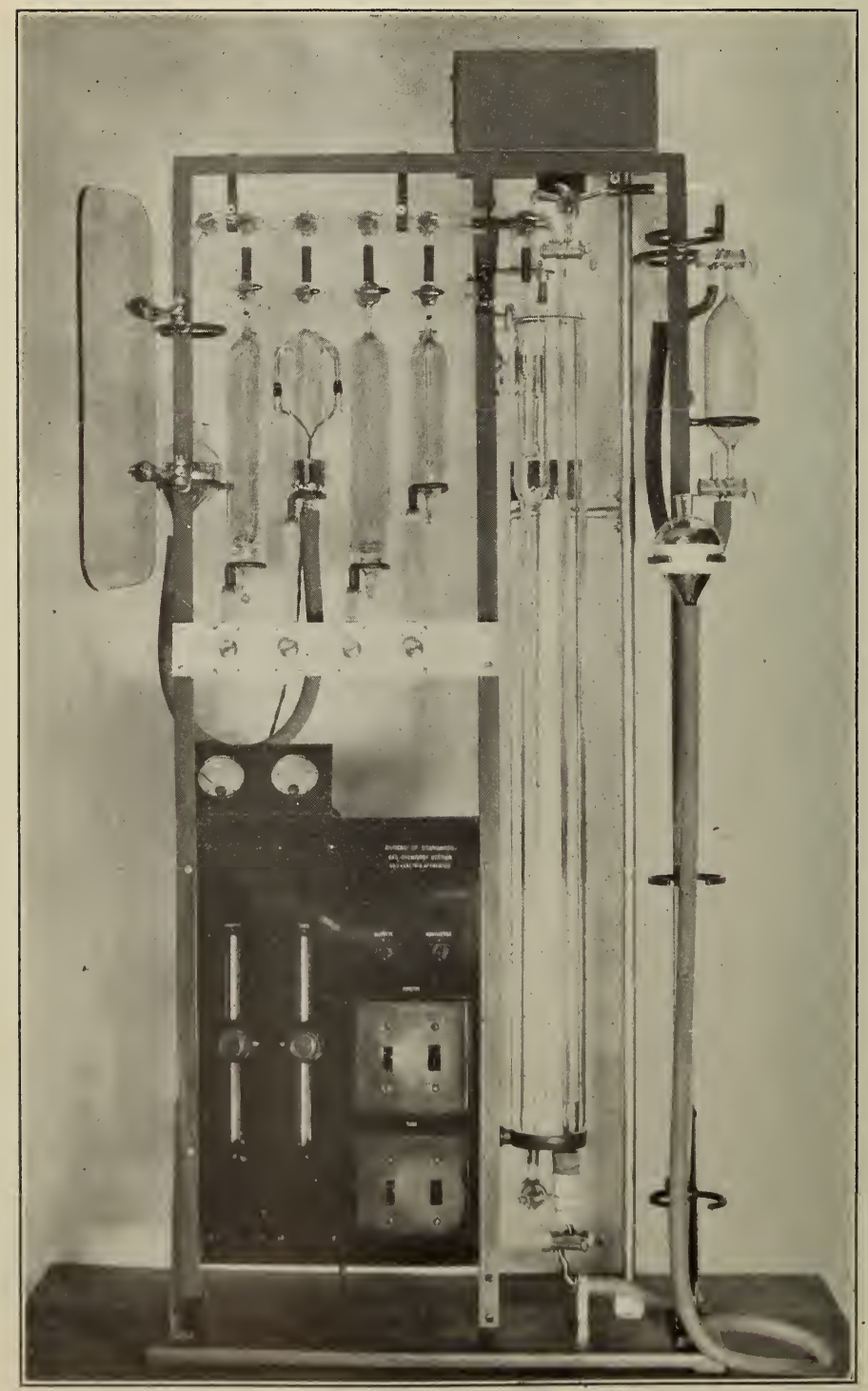

ligure 15. The special model 
at the bottom insure the necessary rigidity. This type of support is superior to the usual wooden mounting. It is free from warping and makes the apparatus much more accessible.

The water jacket rests in the ring $F_{6}$ and is secured at the top by two friction clips $F_{7}$. The sampling pipette rests on a split ring and is held at the top by a friction clamp $F_{8}$. The absorptioii and combustion pipettes rest on split rings $F_{2}$, which are mounted on sliding supports $F_{3}$ secured to the crossbar $F_{4}$.

A detail drawing of the pipette support is given in Figure 17. The rings are secured to the sliding supports by machine screws, and are, therefore, adjustable to accommodate pipettes of various widths. The sliding supports are guided by the grooved pieces $F_{9}$ and secured in place by the set screws $F_{10}$. The spacers $F_{11}$ fix the crossbar $F_{4}$ at the proper distance outward from the frame, so that the pipettes may be connected to the distributor without off-set. The whole pipette support is chromium plated.

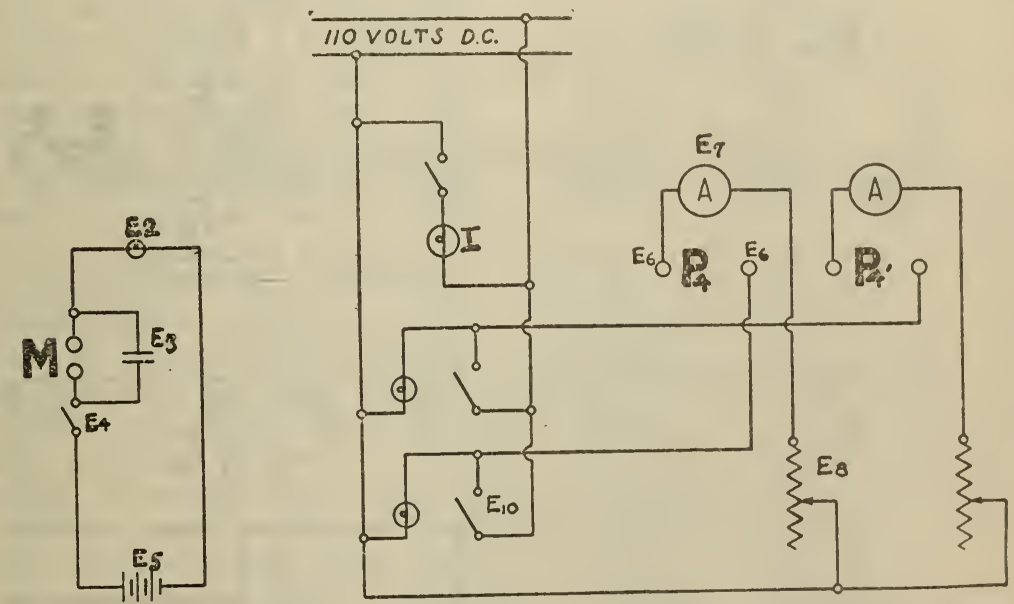

Figure 16.-Wiring diagrams for the manometer and combustion pipette circuits

The 3-volt manometer circuit is shown at the left. The 110-volt circuit shown at the right

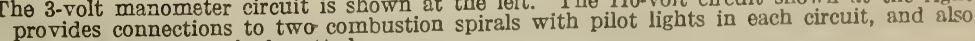
provides current for the burette lamp.

The apparatus support is designed to permit the removal of any part of the apparatus without disturbing other parts. The glass parts are so easily accessible that it is possible to completely assemble or dismount the apparatus in a few minutes.

\section{STOPCOCKS}

It is very important that only the finest stopcocks be used in the construction of the apparatus. The stopcocks ordinarily supplied are not satisfactory. While no high vacua obtain within the apparatus, stopcocks suitable for this kind of work should be used. This does not imply a mercury seal, but rather specifies the finest grade of grinding, which is often referred to as the "mirror finish." The bores of key and barrel should register and be free from chipping.

When the stopcock is properly lubricated there should be no bubbles, films, or streaks of air between the surfaces of key and barre!. A satisfactory lubricant is the general grade described by Shepherd 
and Ledig. ${ }^{14} \quad$ A technique of lubrication is also given in the same paper. The reader may find the details given in this paper of some value. An abstract is given in the following paragraphs:

The general lubricant is made from- Parts

Rubber (pale crêpe, freshly milled, free from all dirt and lint) _ _ 6

Vaseline

Paraffin (m. p. about $40^{\circ}$ to $45^{\circ}$ C.) $\ldots \ldots \ldots$

The vaseline and paraffin are melted in a large porcelain casserole, and the rubber is added in several portions. The mixture is placed in a thermostated oven and stirred continuously for 190 hours at $155^{\circ}$ to $160^{\circ} \mathrm{C}$. It is then transferred to 2-ounce ointment cans and chilled on ice immediately, care being taken to prevent the condensation of water in the lubricant.

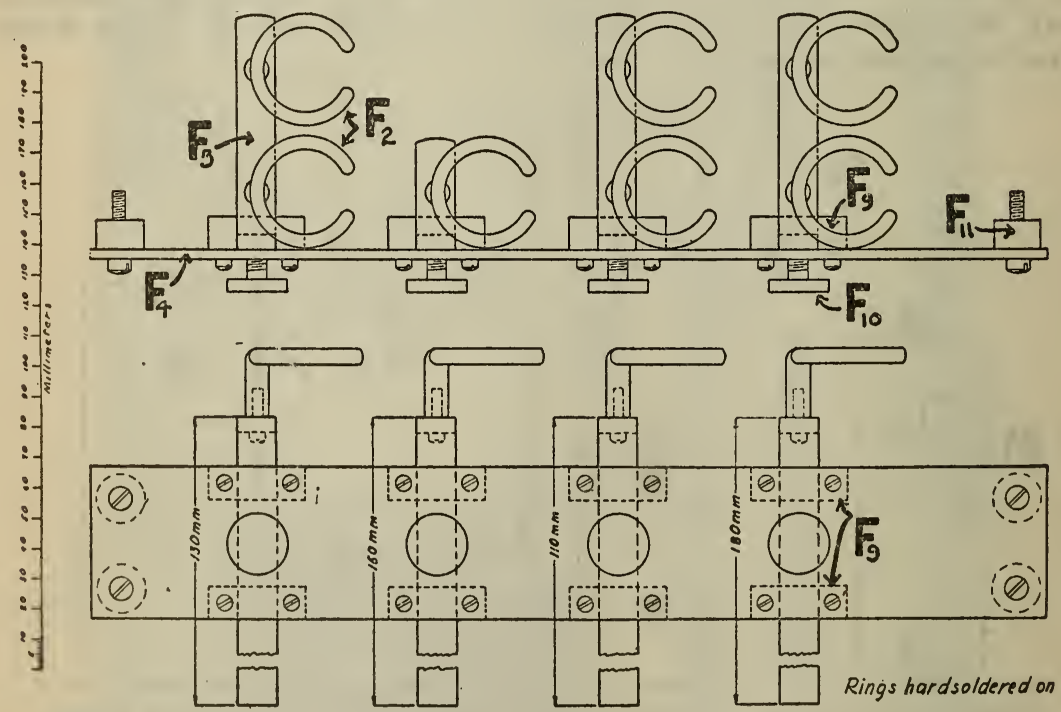

FIGURE 17.-The pipette support

There are many methods of lubricating a stopcock, and not all are entirely satisfactory. A method familiar to many acquainted with high-vacuum technique may be recommended. The lubricant is applied in two parallel longitudinal streaks, one on either side of the key and away from the bore. The streaks should be as thin as possible, and contain only enough lubricant to flow entirely around the key. The lubricant so placed, the key is held above a soft Bunsen flame, so that the grease just melts to form a smooth ridge of approximately semicircular cross section. The key is allowed to cool and then carefully inserted into the barrel so that the bores of key and barrel coincide. The key is pressed downward into place, with little, if any, turning, the lubricant forming V's on either side of the bore

14 Rubber Stopcock Lubricants for High Vacuum and Other Uses, Ind. Eng. Chem., 9, p. 1059; 1927. 
and pressing out all air films until it has flowed smoothly around the entire grinding.

The stopcock key should never be turned with a spasmodic jerk, but rather should be rotated with a slow, smooth motion.

\section{METHODS OF ANALYSIS AND TECHNIQUE OF OPERATION}

The portion of the following section which deals with the actual technique of operation is written largely for the benefit of the inexperienced operator and also for the analyst who has been accustomed to using the ordinary commercial types of apparatus. It is intended to give the instructions in sufficient detail so that a clear understanding of the manipulative processes will be obtained, and a great deal of trouble avoided. Several advantages of the apparatus are brought out during the discussion of the operating technique, and the methods given for making exact analyses are somewhat different from those usually employed. The detail may prove a bit tiresome to one more familiar with gas analysis, and from such a reader consideration is asked where it is required.

It is well to point out at this time just what is meant in this paper by a "technical" and an "exact" analysis. These terms have been used in textbooks on the subject and have consequently assumed a certain significance to which they are no doubt entitled, provided everyone knows what is meant. The "technical" analysis is a rough approximation to truth and the "exact" analysis is a step further along in that general direction. The "exact" analysis is not exact, but is merely designed to catch up some of the loose threads of the technical effort and weave them into a fabric that is still in need of some patching before it can be made into a totally presentable garment. The usual "exact" analysis is actually a technical analysis performed with somewhat more than ordinary care. The field of exact analysis has not been well covered. So far there have been but few explorers in this more difficultly accessible territory. In the present paper, the term exact analysis has been misused to partially conform to general practice, although it is hoped that the analyses to be achieved under this classification may be somewhat more accurate than are usually reported as "exact." And certainly the technical analyses spoken of herein should be of a better grade than those generally performed under that name-perhaps the equal of many so-called "exact analyses."

\section{SAMPLING}

A great deal has been said concerning various methods of taking the gas sample. Special conditions often obtain and may require other than the routine technique. It is beyond the scope of the present paper to report the rather ingenious methods devised to meet these unusual cases. It will be assumed that the sample is readily accessible.

The important fact is this: The analysis can be no better than the sample. This simple fact has been stated repeateily-and as repeatedly ignored. The analyst has only to ask himself: "Is this the gas that will tell me the story I must know?" And not until the 
question is given an affirmative should the sample be taken. (The attention of the engineer is also respectfully referred to that question.) Two questions follow this: "Is the sample secured within the container identical with the gas drawn from the source of supply?" And, finally: "Is the sample transferred to the analytical apparatus of exactly the same composition as the gas within the sampling container?"

A pair of honest affirmatives to the last questions may be claimed by observing simple precautions. The stopcocks of the sampling pipette $\left(P_{1}\right)$ must be trustworthy. This means that they have been carefully ground to a "mirror" finish, as have all of the stopcocks of the analytical apparatus; and that they have been properly lubricated. ${ }^{15}$

The leveling bulb $L_{2}$ (fig. 12) is connected to the lower outlet of cock 15 of the sampling pipette, and the pipette is then filled with clean mercury. A tube of small bore and minimum length is connected to the source of the sample and to the upper outlet of cock 14. This sampling line is then flushed with gas from the source of supply by turning cock 14 to connect the line to the atmospheric outlet of 14. The stopcock is then turned to connect the source to the pipette, and the sample is taken in over mercury. If the gas at the source is not under pressure, a $120^{\circ}$ stopcock similar to cock 3 of the burette is connected to the upper outlet of 14 , and the sampling line is connected to one of the two free outlets of this additional cock. A sample is then drawn into the pipette by lowering $L_{2}$, and this gas is expelled, without disconnecting the sampling line, through the third or atmospheric outlet of the $120^{\circ}$ cock. Air which was originally in the sampling line is thus displaced, and a fresh sample may now be taken for analysis. If an aspirator is available, it may be connected to the atmospheric outlet of 14 and the sampling line flushed by drawing gas through the aspirator.

The sample should be taken under slight pressure whenever possible. When rubber connections are used they should be secured with waxed floss in the manner previously described, unless the sampling condition: permit the maintenance of a positive pressure within the system at all times. The sample should be left in the pipette under pressure, and should be analyzed as soon as possible after it is taken.

The sampling pipette is mounted on the apparatus support as shown in Figure 12. If the pipette has been disconnected from the leveling'bulb $L_{2}$ in transferring it to the apparatus, it will be necessary to displace air from the tube connecting $L_{2}$. This is done by opening cock 15 to its atmospheric outlet and allowing mercury from $L_{2}$ to flow slowly upward through the bore of the cock. Similarly, air contained in the capillary sampling connection $S$ is displaced by mercury from the burette. The mercury is allowed to drain from the atmospheric outlet of 14 and may be caught in a rubber tube leading to a beaker, or a steel tube may be mounted onto the frame in such a way as to act as a mercury drain and a support for the atmospheric outlet of 14. The latter arrangement is pictured in the photograph of the special model. (Fig. 15.)

If this technique is carefully followed, the sample entering the burette should be identical with the sample drawn from its source of supply.

\section{PREPARATION OF THE APPARATUS FOR AN ANALYSIS}

(Refer to fig. 12 unless otherwise specified)

Burette, manometer, and compensator.-The burette and manometer should be cleaned with sulphuric-chromic acid before they are mounted on the frame. The compensator must contain a few milliliters of water. The manometer is dried and very clean mercury is introduced with the ground cap $A$ removed. The amount of mercury in the manometer should be sufficient to bring the meniscus within approximately $0.5 \mathrm{~mm}$ of the platinum contact (n) (fig. 4 ) when the manometer is leveled and both arms are at atmospheric 
pressure. The leveling bulb $L_{1}$ should contain enough clean mercury to completely fill the burette and leave an excess within the bulb. All air bubbles, which may be in the rubber tubing connecting the bulb with the burette, must be displaced by mercury flow.

Absorption pipettes.-For the sake of completeness, the preparation of the reagents used in the illustrated analysis may be described. The reagent used for the removal of carbon dioxide in the absorption pipette $P_{2}$ is a potassium hydroxide solution. This is prepared from a solution of potassium hydroxide in water $(800 \mathrm{~g} \mathrm{KOH}$ per $1,000 \mathrm{ml}$ of solution) which is then cooled to a temperature several degrees lower than will exist where the apparatus is used. The clear solution decanted from the deposit of carbonate and excess potassium hydroxide is satisfactorily pure and will not deposit solid within the pipette. Its specific gravity should be approximately 1.55 at $20^{\circ} \mathrm{C}$. It may be used for making up both the $\mathrm{KOH}$ and $\mathrm{KOH}-$ pyro solutions. For the absorption of carbon dioxide in the pipette $P_{2}$, this solution is diluted by adding 50 to $60 \mathrm{ml}$ of water to each $100 \mathrm{ml}$ of concentrated potassium hydroxide solution.

The reagent used for the removal of oxygen in the absorption pipette $P_{3}$ is an alkaline pyrogallol solution. This is made by dissolving crystalline pyrogallol in a minimum amount of hot water and adding this solution to the concentrated potassium hydroxide solution as prepared above. Fifteen to seventeen grams of the pyrogallic acid dissolved in about 5 to $10 \mathrm{ml}$ of hot water is added to each $100 \mathrm{ml}$ of the concentrated potassium hydroxide solution in the manner decribed below. The resulting solution closely approximates the one recommended by Anderson, ${ }^{16}$ who found a solution containing $15 \mathrm{~g}$ of pyrogallol per $100 \mathrm{ml}$ of potassium hydroxide solution of 1.55 specific gravity to be satisfactory. Anderson observed foaming in a reagent containing more than $15 \mathrm{~g}$ of pyrogallol/100 ml of solution, but this apparently does not occur in a pipette of the type of $P_{3}$ when $17 \mathrm{~g}$ of pyrogallol/100 $\mathrm{ml}$ of solution is used.

In order to prevent air from reaching the reagents a layer of light mineral oil, about 10 to $15 \mathrm{~mm}$ in depth, is poured over the reagent in the reservoir arm of the pipette. This also permits the preparation of the pyrogallol solution within the pipette itself and out of contact with air. The potassium hydroxide solution is first introduced, the oil is placed over this solution, and the pyrogallic acid solution in water is introduced beneath the layer of oil from a pipette. Mixing is obtained by several passages of a large volume of nitrogen from the burette to the pipette.

The amount of reagent put into the pipette should be just sufficient to completely fill the pipette without overflowing from the reservoir arm when the pipette contains $100 \mathrm{ml}$ of gas. Account must also be taken of the layer of mineral oil when this maximum volume of reagent is determined.

A record should be kept of the amount of oxygen absorbed, in order that the absorbing capacity of the pyrogallol solution will not be exceeded.

The absorption pipette $P_{5}$ is ordinarily employed as a reservoir for nitrogen used in flushing the distributor, and contains alkaline pyrogallol solution. It can be used for other absorptions as these may

16 R. P. Anderson, J. Am. Chem. Soc., 1, p. 587; 1915. 
occasionally become necessary. If such necessity is more than occasional, the distributor and apparatus should be extended to accommodate the requisite number of pipettes.

Many of the additional absorptions which may be desirable involve reactions which are apt to be conflicting or even not satisfactorily quantitative. The reagent may not be quantitatively selective, and the gas mixture may present a combination which is difficult to handle in this type of analysis. The well-known reagents are discussed by Dennis, ${ }^{17}$ and some of their limitations are cited. The reader who is not familiar with this subject will find a good discussion given by Dennis.

Combustion pipette.-The platinum helix over which the combustion occurs is placed in the pipette in the manner previously described. The pipette is then filled with clean mercury from $L_{3}$, leaving a slight excess of mercury in this bulb. Care is taken to displace all air from the side arms of the pipette. The mercury is not allowed to flow into the bore of stopcock 11 .

Test for leaks. - When the apparatus has been assembled and all rubber connections secured with waxed floss, the stopcocks properly lubricated, and the jacket $J$ filled with water, the apparatus should be tested for possible leaks. The average beginner using the average apparatus will experience a great deal of difficulty which is directly chargeable to this source of error. A large leak lends itself to early discovery; but a small leak may be insidious, appearing and disappearing in the final results in most perverse ways. Such sources of error are so difficult to detect that the beginner frequently confuses them with inability to master the technique. The present apparatus should improve this situation. It will be remembered that all stopcocks are made to specifications far more rigid than the average, and that a careful technique of lubrication has been prescribed, and finally that a trustworthy method of securing rubber connections has been given. The combustion pipette $P_{4}$ replaces a well-known type that is apt to cause the most serious sort of errors due to leaks whose presence may not be suspected. So little difficulty from leakage in this apparatus has been experienced that it has become of minor importance. (This is true only if the rubber connections are kept in excellent condition.)

It is always advisable to test the assembled apparatus in order to make perfectly sure that it is free from leaks.

This is done by taking a small measured volume of air into the burette, closing all stopcocks, and reducing the pressure within the burette by lowering' $L_{1}$ to $R_{1}$. At the end of 15-minute intervals volume readings are taken and compared with the original volume, each stopcock being opened in turn so that the leak, if present, may be located at the termination of the particular 15-minute interval during which leakage occurred. The test is then repeated with a pressure greater than atmospheric. Volume readings are to be taken in the manuer to be described in the succeeding section.

\section{CONSIDERATIONS PRELIMINARY TO THE ACTUAL ANALYSIS}

When the apparatus has been assembled and prepared according to the directions just given, and the sample has been taken in $P_{1}$ and transferred to the apparatus, the actual operation of analysis is begun. It will be well to go through the steps of a complete analysis, and for

${ }_{17}$ Dennis, Gas Analysis. The Macmillan Co., New York. 
this purpose we will assume that the sample contains carbon dioxide, oxygen, methane, carbon monoxide, hydrogen, and nitrogen.

It is, of course, understood that a volume of this mixture must be measured, and that each constituent must be renoved and the contraction in volume resulting from its removal must be determined. The comparison of these diminishing volumes with that of the original sample affords the basis for determining the various percentages of the components. It is therefore necessary that each volume measured be corrected to the same temperature and pressure. This is automatically accomplished by use of the manometer-compensator unit, which is a modification of the usual temperature-pressure compensation system. The compensator itself is of the same size as the burette and placed parallel to it. Both are surrounded with water. The temperature of one closely approximates the temperature of the other at all times.

The pressure in the compensator is fixed at the beginning of an analysis by closing $A$, and the pressure of the gas which is measured in the burette is always adjusted to this same fixed pressure by means of the manometer which indicates when this fixed pressure has been obtained within the burette. The gas within the burette must be saturated with water before every measurement, and the compensator contains water, so that the vapor pressure within one balances the vapor pressure within the other. The series of gas volumes which are to be compared are, therefore, converted to uniform conditions of temperature, pressure, and humidity without calculation.

Another point should be clearly understood before describing the actual steps of the analysis. It has been pointed out that the distributor connecting the parts of the apparatus is of the gas-filled type. An inert gas must be used, since no portion of this gas must react during the analysis. Nitrogen remaining after the absorption of oxygen from air is ordinarily used, since this is conveniently prepared within the apparatus itself. The pressure of the gas within the distributor must be the same as the fixed pressure of the compensator at the beginning of an analysis and at all times during the analysis when a volume is to be measured. It is obvious that if this condition did not exist, the gas volumes measured in the burette would be larger or smaller than they should be by the amount of gas drawn from the distributor at a pressure less than that of the compensator or compressed into it at a pressure greater than that of the compensator.

Water upon the burette wall.-The original sample and its various fractions are saturated with water before each volume is measured. This is done by maintaining a film of water upon the wall of the burette. The left-hand outlet of stopcock 3 is immersed in distilled water contained in a small beaker. (See fig. 15. The platform supporting this beaker swings aside to permit the removal of the beaker.) A few milliliters of water is drawn into the burette over the mercury, the mercury is lowered to the $100 \mathrm{ml}$ mark, and then slowly raised, and the surplus water expelled. The wall of the burette will retain enough water to saturate the gas. No water should be left on the mercury, since this would interfere with the reading of the position of the meniscus. Since the potassium hydroxide and alkaline pyrogallol solutions both remove water from the gas, the presence of water upon the wall of the burette must be checked after the completion of each absorption. If the water is not present, serious errors will result. If 
the water film disappears during the course of the analysis, it may be renewed by displacing all gas from the burette, temporarily storing the gas in the particular pipette in use at the time and again wetting the wall of the burette.

Difference in analytical procedures.-The method of supplying oxygen for the combustion will determine the actual procedure. Oxygen may be obtained by using air and multiplying the measured volume of air by 0.2095 to obtain the volume of oxygen used. Since this leaves a large volume of nitrogen which must be measured after the combustion, it is necessary to use a small sample of gas for the combustion analysis. The accuracy is accordingly decreased. For this reason many analysts prefer to use pure or nearly pure oxygen. This may be obtained from an auxiliary apparatus designed to generate and purify the gas, or from a cylinder of compressed oxygen, which has been obtained from air separation, and has been previously analyzed to determine the percentage of inert gas and establish freedom from combustible vapors.

The analytical procedure is somewhat different in the two cases, and, accordingly, will be outlined for each. The procedure undertaken for exact analysis is also different from that used for technical or approximate analysis, and the differences will be pointed out as the instructions are developed. It will be observed that an exact analysis requires many extra steps and a great deal of care and patience.

\section{ANALYTICAL PROCEDURE; AIR USED FOR THE COMBUSTION}

It is now assumed that the apparatus is prepared for the analysis as previously described. The pipettes are filled with reagents to the etch marks on the capillary stems, or, in the case of $\mathrm{P}_{4}$, with mercury to the bore of stopcock 11. The burette is filled with mercury, and the manometer is standing at approximate balance with $A$ open to the atmosphere. The sample pipette is mounted in place, and contains a mixture of carbon dioxide, oxygen, methane, carbon monoxide, hydrogen, and nitrogen. We may now proceed.

Filling the distributor and manometer.-The first step is to fill the distributor and the arm of the manometer connected thereto with nitrogen at the pressure which is to be fixed within the compensator.

To do this, 2 is turned to 3,3 to the atmosphere, $L_{1}$ placed on $R_{1}$, and 1 is opened until about $10 \mathrm{ml}$ of air has entered the burette. Cock 1 is then closed, 2 turned to the distributor, and 4 to connect the manometer. Cock 1 is now slowly opened, the mercury in the manometer arm connected to the distributor rises, and 1 is turned to the constriction as the mercury nears the bore of cock 4 . When the mercury reaches this bore, 1 is closed. The manometer is shut off by turning 4 upward. Air has now been displaced from the manometer. Cock 2 is turned to $S$ and 1 opened to admit about $100 \mathrm{ml}$ of air to the burette. The oxygen is now removed from this air. Cock 1 is closed, $L_{1}$ placed on $R_{4}$, and 2 turned to the distributor. (Stopcocks $4,5,6$, and 7 are turned upward.). Stopcock 8 is turned to connect $P_{5}$ and shut off the balance of the distributor to the left. Cock 1 is opened slowly, and when the volume. within the burette has been compressed several milliliters, so that there is no danger of drawing reagent into the distributor, 10 is opened. Air from the burette now passes into $P_{5}$ containing alkaline pyrogallol solution, and the removal of oxygen is started.

Refer now to Figure 9. It will be seen that the handle of stopcock 10 is marked at one end to indicate the direction of gas flow. When the marked end points upward the stopcock is turned to withdraw the gas from the pipette, and conversely when the marked end points downward the stopcock is in the proper position to introduce the gas into the pipette. On the other hand, when the 
sample is initially introduced into the pipette, 10 is turned upward until the reagent drains from the the left-hand capillary, and then turned downward to conduct the absorption. If this were not done, the reagent in the left-hand capillary would not drain out, and when 10 was turned upward to return the gas to the burette, the reagent trapped in this tube would immediately be drawn into the distributor, which is one of the major tragedies of gas analysis

Three passages are sufficient to remove the oxygen. After the final passage the nitrogen is returned to the burette, the level of the reagent in the pipette being adjusted to the etch marks on the capillary stems just below stopcock 10 , after which 10 is closed, and $\gamma$ is turned to the position $\vdash$. It may be noted here that the alkaline pyrogallol solution is a comparatively viscous reagent, and returns slowly through the small orifices of the platinum distributing plate used in this type of absorption pipette. The ordinary technique for returning the gas from the absorption pipette to the burette is to turn the pipette stopcock upward to connect both capillaries to the burette. If the stopcock is turned downward for the return of the gas, reagent is immediately drawn up the capillary gas inlet and into the distributor. This will happen in a pipette such as $P_{2}$, but on account of the comparatively slow flow of reagent through the distributing plate $\left(P_{3}\right.$ and $\left.P_{5}\right)$, the following technique is used. The pipette stopcock is allowed to remain in the downward position for delivery of gas to the pipette. The pressure is reduced by allowing the mercury within the burette to drop about $20 \mathrm{~mm}$. The reagent then flows through the perforated plate and into the capillary within a few seconds, but rises in the capillary at an easily controlled rate. The pipette stopcock is then turned to the normal position for the return of the gas to the burette. This technique is not absolutely necessary, but will save time. The reagent is adjusted to the etch marks on the pipette capillaries by turning stopcock 1 to the constricted bore.

Nitrogen now fills all of the distributor except the capillary leads from stopcocks 5,6 , and 7 to stopcocks 13,12 , and 11 , and the spaces within the capillary stems of $P_{2}$ and $P_{3}$ above the reagents. The air inclosed in these capillary spaces must be displaced.

This is accomplished by diluting these small volumes with the large volume of nitrogen within the burette. Nitrogen is first passed from the burette to $P_{4}$, returned, and passed into $P_{2}$, returned, and then passed into $P_{3}$, where the residual oxygen is removed during one passage. The reagents are adjusted to the etch marks on the capillary stems of the pipettes $P_{2}$ and $P_{3}$, and mercury to the bore of cock 11, as the gas is returned from each of these pipettes.

The burette is now connected to $P_{5}$ and all but about $10 \mathrm{ml}$ of nitrogen is passed into this pipette for storage and future use after which 1 is closed. Cock 10 is closed, 8 turned to the position $\vdash$, and 7,6 , and 5 turned to the position $T$.

The pressure within the distributor and manometer is now balanced against the compensator.

Stopcock 2 is closed, 1 is opened, and the pressure within the burette is adjusted to approximately that of the atmosphere by raising and lowering $L_{1}$ which is momentarily held in the hand for this purpose. A comparison of the mercury levels within $B$ and $L$ will indicate when the gas in $B$ is under approximately atmospheric pressure. When this condition is reached, 1 is closed, $L_{1}$ placed on $R_{4}$, and 2 opened to the distributor. Cock 4 is now turned in the position $T$, which simultaneously connects the distributor and the burette to the manometer. The mercury within the arm of the manometer connected to the distributor will fall, but not enough mercury will have been admitted to the compensator arm of the manometer to bring the meniscus here in contact with the platinum reference point. Cock 1 is now slowly turned to only partially open the full bore, whereupon mercury will approach the platinum point. Cock 1 is closed when the mercury is within approximately $1 \mathrm{~mm}$ from this point. $A$ is now closed, thus shutting off the compensator and fixing the pressure therein. $A$ is not touched during the remainder of the analysis, and all gas volumes are measured by comparison with the fixed compensator pressure. Cock 1 is now opened to the constriction. The mercury within the compensator arm of the manometer will now flow very slowly upward until it touches the platinum point. At the instant when the 3 -volt circuit is closed, and the miniature lamp flashes on, 1 is closed.

All other pressure adjustments are made in this manner, except that, of course, $A$ is not turned, and the control cock 1 is turned 
from the partially opened full bore to the constricted bore and then closed, rather than being closed before turning to the constricted bore as was necessary above. The end point is always obtained with the mercury rising toward the contact point, never the reverse. If for any reason the contact point is accidentally overrun, 1 is closed, $L_{1}$ lowered to a ring below the mercury within the burette, 1 carefully opened until the mercury falls below the contact point, and the operation of adjusting the pressure repeated.

The distributor and the arm of the manometer connected thereto now contain nitrogen under the fixed compensator pressure. Cock 2 is turned to 3 , and the nitrogen remaining in the burette is expelled to the atmosphere, the mercury in the burette being forced just past stopcock 3. The apparatus is now ready for the introduction of the sample.

Introduction of the sample.-The sample pipette is connected to stopcock 3 of the burette by the capillary glass tube $S$.

Air is displaced from this line by opening 14 to the atmosphere and forcing mercury from the burette through the line. ( $L_{2}$ has already been connected to 15 and the air displaced by mercury from $L_{2}$ through the atmospheric outlet of 15.) $\quad L_{2}{ }^{18}$ is now opened to $P_{1}$ through 15 , thus compressing the sample in $P_{1}$. Stopcock 14 is opened to the burette, stopcock 1 closed, $L_{1}$ placed on $R_{1}$, and stopcock 1 opened slowly to admit the sample to the burette. When the mercury in the burette has reached a point somewhere between the 84 and $86 \mathrm{ml}$ marks, 2 and 14 are closed in the order named.

The sample taken is much larger than it will be possible to use for the combustion, so that it will be necessary to do something about this later on, which will be disclosed at the proper moment. However, carbon dioxide and oxygen are apt to occur in very small amounts in some gas samples, and for this reason it is obviously necessary to take as large a sample as possible for their determination by absorption.

Measurement of the sample.-The gas sample taken, into the burette is now under positive pressure. Before the burette is opened to the manometer, the pressure within the burette is adjusted to approximately atmospheric.

This is done as before by opening 1 and manipulating the leveling bulb $L_{1}$ by hand until the mercury within the bulb and burette are roughly at the same level. Cock 1 is then closed, $L_{1}$ placed on $R_{1}$, and 2 and 4 opened to connect the manometer to the burette. If the pressure within the burette is greater than the compensator pressure, the mercury within the compensator arm of the manometer will rise over the platinum contact. Cock 1 is then opened until the mercury drops several $\mathrm{mm}$ below the contact point, after which it is closed and $L_{1}$ is placed on $R_{2}$. If, on the other hand, the pressure within the burette is lower than the compensator pressure, the mercury within the compensator arm of the manometer will fall below the contact point, in which case 1 may be closed and $L_{1}$ placed on $R_{2}$ immediately.

It will be observed that the rise and fall of mercury within the compensator arm of the manometer, which contains the zero or reference contact point, follow the rise and fall of mercury within the burette. No confusion should result, since the system responds to the natural reaction of the operator, who accordingly has no inhibitions to overcome as he may in the case of the usual manometer

$18 \mathrm{~J} . \mathrm{R}$. Branham has sugrested a different technique. The atmospheric outlets of 14 and 15 are connected with a short length of rubber tubing. Air may then be displaced in one operation by mercury from $L_{2}$ which is forced through 15,14 , and 8 . This also eliminates the necessity of a drain tube to catch excess mercury flowing from the burette through 14 . 
system which is ingeniously devised to confuse the tyro by placing the reference arm of the manometer in such a position that the direction of flow of mercury within the burette is reversed in the manometer. Furthermore, it will be remembered that the position of the manometer permits the distributor and burette pressures to be balanced simultaneously. Since the manometer is usually connected to a stopcock corresponding to 2 and the distributor to a stopcock corresponding to 3 , it is impossible to do this in an ordinary apparatus. The usual technique requires several alternate pressure adjustments. The burette must be balanced against the compensator, then the distributor opened to the burette, then the burette balanced against the compensator, and so on until a pressure equilibrium is thought to have been reached.

The burette is graduated to $0.2 \mathrm{ml}$, and the distance between etch marks is about $1.2 \mathrm{~mm}$, so that it is possible to estimate volumes to $0.05 \mathrm{ml}$ and sometimes more closely. The burette is read with one of the illuminating devices previously described, and in such a manner that the tip of the meniscus where the reading is taken presents the appearance of a curved black line.

Absorption of carbon dioxide.- The next step in the analysis is the absorption of carbon dioxide. Since the manometer arm adjacent to the distributor may contain some of the gas sample, the introduction of which often occurs during the process of pressure adjustment, the gas within this arm is displaced by lowering $L_{1}$, opening cock 1 , and allowing the mercury in the manometer to rise to stopcock 4. Cock 1 is turned to the constriction for the final control, and the mercury is stopped just short of the bore of cock 4, which is then closed to the position $\perp$.

The pressure of the gas within the burette is now reduced, and must be brought back to atmospheric or slightly in excess thereof before opening stopcock 13 to admit the gas to $P_{2}$ for the absorption of carbon dioxide.

The routine of absorption is as follows: Cock 1 is closed, $L_{1}$ placed on $R_{4}, 1$ is opened until the mercury in the burette rises to the mark corresponding to the original volume measured, 5 is turned to the position $\vdash, 13$ is then opened first upward to drain the reagent from the capillary as before described, then downward to introduce the gas through the bubbling tip. The passage should be made in about 30 seconds. After the passage, 13 is turned upward, 1 is then opened to the constriction and $L_{1}$ placed on $R_{1}$. This affords an opportunity to check the setting of 13 , since the reagent will immediately rise in the capillary inlet of $P_{2}$ if 13 is improperly adjusted, and the fact that 1 is turned to the constriction will permit the operator time to rectify a mistake bcfore the reagent has been drawn into the distributor. Cock 1 may be opened if 13 is correctly turned, and the gas returned to the burette until the reagent is within, say, 1 $\mathrm{cm}$ of the dome of the pipette. Cock 1 is then closed, $L_{1}$ replaced on $R_{4}, 1 s$ turned downward, and 1 again opened. Three such passages will remove carbon dioxide, and the gas is finally returned to the burette for measurement, the potassium hydroxide solution in $P_{2}$ being adjusted to the etch marks by opening 1 to the constricted bore. Cock 19 is closcd, 4 is opened to the distributor and the burette, and the pressure balanced approximately.

If the wall of the burette is moist, the gas within the burette should become sufficiently saturated at the end of two minutes. The pressure is then balanced against the compensator. The volume of the gas is read and noted. The difference between the volume of the sample and this volume represents the volume of carbon dioxide absorbed. If the lower portion of the burette wall is moist and the 
upper portion is dry, the gas within the burette reaches saturation very slowly, sometimes requiring 20 to 30 minutes contact. If this condition obtains, time may be saved by introducing water within the burette while the sample is stored in the absorption pipette. The measurement of a gas which is not saturated with water introduces considerable error in the analysis. Errors arising from this source are frequently made in ordinary practice, and the analyst should take especial precautions to avoid them.

Absorption of oxygen.-The gas is now displaced from the arm of the manometer connected to the distributor, the pressure in the burette again adjusted to slightly in excess of atmospheric, and the remaining gas sample passed from the burette into $P_{3}$, stopcock 6 being turned to the position $\vdash$. The absorption is conducted as before, except that at the end of the second passage the gas is passed from the burette into $P_{2}$. This step removes the oxygen which was retained as part of the gas left in the capillaries of $P_{2}$ between the reagent and cock 13, and in the capillary between stopcocks 5 and 13 . The total amount of oxygen thus removed by dilution will usually be small, and this step may be omitted for a technical analysis; but for exact analysis the operation is included. The third passage should remove the oxygen unless it was present in a larger amount than 20 per cent, in which case a fourth passage is advisable. After the removal of the oxygen, the gas is returned to the burette and the remaining volume measured as before. The difference between the volume after absorption of carbon dioxide and this volume represents the volume of oxygen absorbed.

Precautions. - It will be remembered that the solutions in $P_{2}$ and $P_{3}$ remove water vapor from the gas. The presence of water on the wall of the burette should always be assured before measuring the final volume after absorption. If water has disappeared from the burette, it must be added while the gas is stored in one of the two pipettes. Furthermore, the solutions should not be used after their absorbing power has been expended. The potassium hydroxide solution presents no real difficulties, since the formation of carbonate crystals indicates the need of its replacement.

It is often desirable to check the completeness of absorption with the alkaline pyrogallol solution. This is easily done by conducting the absorption in the ordinary manner, reading the residual gas volume, and then passing the gas back into the reagent and again reading the residual volume. All guesswork is eliminated by this operation.

The combustion.- The volume of oxygen taken should be in excess of the volume required to burn the gases present. In some cases a knowledge of the source of the gas sample may roughly establish its approximate composition, in which case the oxygen requirement may be more closely approximated than in the case of a completely unknown sample. In the case of an unknown sample the oxygen for combustion should be calculated on the basis of the component requiring the largest amount. This will ordinarily represent a large excess, but subsequent check analyses may be performed without the inconvenience of handling volumes larger than may be necessary.

In the present instance the gas mixture selected for analysis contains hydrogen and carbon monoxide, each of which requires 0.5 
volume of oxygen per volume; and methane, which requires 2 volumes of oxygen per volume. If the sample were pure methane the oxygen required for a $10 \mathrm{ml}$ sample would be $20 \mathrm{ml}$, and the air required would be approximately five times this, or $100 \mathrm{ml}$, which is the limit of the capacity of the burette. Since the sample is not pure methane this volume of air would represent some excess of the oxygen requirement. The first analysis may then be made upon this basis, but when the composition has been determined, a second and third analysis should be made with a much larger sample taken for the combustion. The operator has only to consider that the volume of air plus sample when burned should not yield a volume of gas (after contraction upon burning) in excess of the capacity of the burette. This is, of course, merely for the sake of convenience, since the contraction after combustion and the carbon dioxide produced upon combustion might be measured in successive steps if this became necessary.

Let us now consider the composition of the gases within the apparatus. At the beginning, the distributor and the distributor arm of the manometer contained nitrogen under the compensator pressure. The burette contained the sample of gas. At the present moment, after the removal of carbon dioxide and oxygen, the distributor and manometer contain some of the original nitrogen plus some of the original gas sample less its carbon dioxide and oxygen, and the burette contains this gas plus some of the nitrogen originally present in the distributor and manometer.

The mixtures are, of course, at the fixed pressure of the compensator. Now if it were possible to use all of the gas sample for the combustion, we could proceed at once. But since we are limited to a smaller volume of sample than is actually present, we must either discard the major portion of the sample within the burette, retaining say $10 \mathrm{ml}$ for the first analysis, or we must discard all of the sample and take a fresh portion from $P_{1}$ for the combustion. Either method is possible, but the first method, that is, discarding a portion of the gas contained in the burette after the absorption of carbon dioxide and oxygen, requires some additional knowledge. It is apparent that in discarding a portion of this gas we have discarded an unmeasured amount of nitrogen, and at the same time left a portion of the gas in the manometer and distributor, which has not been measured with the smaller portion retained in the burette, but some of which will react in the combustion pipette. It is evident, then, that to perform the analysis in this way, we must know the volume of the manometer arm and the volume of the portion of the distributor occupied by this mixture. If these volumes are known, we may then make the calculations which are necessary to determine exactly what volume of gas sample is retained for the combustion. In other words, since the original balanced condition of the system is upset by discarding a portion of sample, we must reestablish a new balanced condition by correcting for the nitrogen removed. The discussion of this technique will be left for the present and considered again with the description of the third analytical procedure.

Meanwhile, the procedure will be continued on the basis that the necessary correction will be made automatically by the apparatus rather than by the operator or, rather, that the apparatus maintains its original balanced condition. When this requirement is made of 
the apparatus, the apparatus in turn retaliates by requiring of the operator some additional manipulation. This will now be explained.

It will be assumed in the following discussion that the operator is sufficiently familiar with each step of manipulation necessary to perform the following operations:

1. Introduce a sample.

2. Adjust the pressure within the distributor or burette or both simultaneously to equal that of the compensator.

3. Measure a gas volume.

4. Conduct an absorption.

The various manipulative steps for each of the operations will, therefore, be omitted, and only the appropriate details necessary to accomplish a new operation will be given.

The procedure which follows is designed for the use of a fresh sample of gas for the combustion.

The gas confined in the distributor arm of the compensator is transferred to the burette, leaving the mercury in the manometer just below the bore of 4 , which is turned to the position 1 . The gas is then expelled from the burette, 2 is now turned to connect the distributor, and about $50 \mathrm{ml}$ of nitrogen from $P_{5}$ is drawn into the burette, after which it is passed into $P_{2}$ and $P_{3}$ and returned to the burette. The manometer is now opened to the distributor and burette, the pressure is adjusted to that of the compensator, 2 is turned to 3 , and the gas expelled from the burette. About $30 \mathrm{ml}$ of air is drawn into the burette and expelled, thus flushing out the atmospheric outlet of 3 . The air for the combustion, about 99 $\mathrm{ml}$, is now drawn into the burette and measured, 4 being turned to the position $1-$ during the pressure adjustment. 5 and 6 are now turned to the position $\perp, \approx$ to the position $\vdash, 4$ to the position $\perp$, and the air is transferred from the burette to $P_{4}$, mercury being taken to the bore of 2 , which is then closed. The pressure within $P_{4}$ is adjusted to approximately atmospheric by raising or lowering $L_{3}$. Cock 11 is closed and 4 turned to the position 1 . (It may be noted that the pressure balance has been slightly altered because of the fact that the gas confined in the capillary connecting cocks 2 and 4 is at approximately atmospheric pressure at the end of the above operation, and should be confined under the fixed compensator pressure. The error introduced is negligible, however, since this volume is not over $0.1 \mathrm{ml}$ and a pressure change of several millimeters of mercury would not effect a change of volume measurable on the burette. If, however, a burette capable of much more accurate measurement is used, this crror may be eliminated by adjusting this pressure to that of the compensator. To do this, 4 is turned to the position $T$ and the adjustment made by lowering $L_{3}$ until the mercury in the compensator arm of the manometer is several millimeters below the contact point. The rubber tubing connecting $L_{3}$ and $P_{4}$ is now closed with a screw clamp, $L_{3}$ is placed on $R_{7}$, and the adjustment completed by admitting mercury to $P_{4}$ at a controlled rate by slowly opening the screw clamp. Cock 11 is closed at the instant the lamp flashes on.)

Cock 2 is now turned to 3,3 to the atmosphere, and mercury from the burette forced through the bore of 3 , which is then turned to $P_{1}$. A fresh sample of gas is now taken into the burette. The volume of this sample, which is to be burned in $P_{4}$, must be small enough so that some oxygen remains after the combustion has taken place. (Refer to previous discussion.) Since this gas contains carbon dioxide and oxygen which will take part in subsequent reactions, a correction must be made for the known amounts of these gases when the analysis is calculated. This volume is measured, pressure adjustment being made with cock 4 remaining in the position $\vdash$. After the volume is measured the gas is displaced from the manometer into the burette, 2 is closed, 4 is turned to the position $\perp$, and the pressure in the burette is adjusted by $L_{1}$ to very slightly in excess of atmospheric.

The current is now applied to the combustion spiral and the rheostat is adjusted until the platinum wire glows with an intensity usually described as a dull cherry red. The glass shield is swung in front of the pipette. $L_{1}$ is placed on $R_{4} . \quad \gamma$ is turned to the position $\vdash, 6$ and 5 to the position $\perp$, and $L_{3}$ is adjusted to place the gas in $P_{4}$ under approximately atmospheric pressure. The pressures in $P_{4}$ and the burette must at first be carefully regulated so that (1) no gas passes from $P_{4}$ back to $B$ and (2) no sudden surge of gas passes from $B$ to $P_{4}$. The flow of gas 
from the burette to $P_{4}$ should be slow and even. Cock 1 is opened to the constriction and 11 is opened a few seconds later. The operator's hand is kept on the rheostat controlling the current. As the gas enters the pipette and combustion starts, the platinum wire will suddenly glow brightly. Its temperature should never exceed something short of white heat or the spiral may fuse. (If this happens, the spiral must be replaced. To do this, the gas flow is inmediately stopped by closing $2,1,11$, and 7 , the gas in $P_{4}$ is transferred over mercury to a reservoir connected to 9 , and returned to $P_{4}$ after the spiral has been replaced and the train refilled with nitrogen from $P_{5}$ ). The temperature of the spiral is kept at this practical maximum during the combustion. It will be necessary to regulate the rheostat to accomplish this, since the spiral will gradually cool as the major portion of the gas is burned. Lower wire temperatures may be used for hydrogen and carbon monoxide than for methane. If the latter gas is not present, the lower temperatures are best, since some trace of nitrogen may be oxidized at the higher temperatures. The operator will soon be able to work out a practical scheme involving the proper rheostat range for various gases, assuming a combustion spiral of uniform length and diameter. The completeness of combustion may, of course, be checked by the method used to assure the completeness of absorption.

Ordinarily four complete passages will be sufficient to complete the combustion. This means eight passages over the wire itself, which is kept glowing at the optimum temperature at all times, as the gas passes from $B$ to $P_{4}$ and $P_{4}$ to $B$. The mercury in $P_{4}$ is arrested at a level about $15 \mathrm{~mm}$ below the combustion spiral upon each return passage to the burette except the last, when this distance is increased to about $30 \mathrm{~mm}$. As the gas cools the mercury will rise, and care must be taken at first to prevent its coming in contact with the heated dome of the pipette.

The number of passages depends on the composition of the gas, variations in temperature of the wire, and variations in rate of flow of gas over the wire. The beginner will do well to check the completeness of combustion until he is familiar with the characteristic behavior of his samples. It is important that the first passage be made slowly, in order that the gas may be reduced to a composition safely below the explosion limits of the mixture. Otherwise, a regrettable accident may occur upon the second passage, and while the operator's person has been provided with protection, his nervous system, and what is more important, the apparatus, may suffer some disintegration. The second, third, and fourth passages may be made with more speed, say 1 minute per passage, while the first should take 2 to 3 minutes.

After the fourth passage some of the gas is left in the pipette, the current is turned off, 11 is closed and $L_{3}$ adjusted to leave the gas in $P_{4}$ under slight pressure as it cools. When the dome of the pipette has cooled, the gas is transferred to the burette, adjusted to approximately atmospheric pressure, the manometer opened, and the burette and distributor adjusted to the compensator pressure. The gas volume is measured. The difference between the sum of the volumes of air and gas taken for combustion, and this volume represents the contraction on burning.

The carbon dioxide produced by combustion is now determined by absorption in $P_{2}$. The gas is first displaced from the manometer into the burette, and after two passages into $P_{2}$ the major part of the gas is returned to the burette and thence transferred to $P_{4}$ (for a technical analysis the spiral is not heated) in order to regain the carbon dioxide left with the gas contained in the train and pipette connection. This step is important, since a small error in the measurement of carbon dioxide produced by combustion is multiplied in the final calculations. The gas is again passed into $P_{2}$ and after the absorption is complete the volume of the carbon dioxide produced is measured and noted. The procedure for an exact analysis differs in that the combustion 
spiral is heated during the passage of the gas after the initial absorption of carbon dioxide. At the termination of the first combustion the partial pressure of carbon dioxide is often high enough to retard the reaction, but after its removal the last traces of combustible gases are burned without delay. The amount of gases burned during this second combustion is usually very small. The additional contraction is measured before the absorption of carbon dioxide.

The oxygen consumed during the combustion is now determined by measuring the excess oxygen remaining after combustion. The gas is accordingly passed twice into $P_{3}$, then into $P_{4}$ and $P_{2}$ to regain (by dilution) the oxygen remaining in the distributor, then into $P_{3}$ to complete the absorption, after which the residual volume is measured and noted. Passages into $P_{4}$ and $P_{2}$ as noted above may sometimes be omitted for a technical analysis, but never for an exact analysis.

This completes the various operations required during the analysis.

Preparation of the apparatus for a second analysis. - Since all of the hydrogen, carbon monoxide, and methane has been burned to water and carbon dioxide, and all carbon dioxide and oxygen removed by absorption, the gas remaining within the apparatus should be nitrogen.

$A$ is turned to admit atmospheric pressure to the compensator, and then closed for the second analysis. (We have already seen how convenient it is to have the fixed compensator pressure approximately equal to that of the atmosphere, because of rough adjustments made by $L_{1}$ and $L_{3}$.) All but approximately $10 \mathrm{ml}$ of the nitrogen is expelled from B. This may be discarded to the atmosphere or stored in $P_{5}$. The distributor and manometer are now balanced against the compensator, and 2 is turned to expel the residual gas from $B$ to the atmosphere.

The apparatus is now in readiness for a second analysis.

\section{ANALYTICAL PROCEDURE; OXYGEN USED FOR THE COMBUSTION}

When oxygen is used for the combustion, rather than air, no large volume of nitrogen remains and it is possible to use the original large sample taken for the absorption analysis. This at once greatly increases the accuracy of the combustion analysis. But here again, if the necessary corrections are to be made automatically "by the apparatus itself," the procedure becomes involved for an accurate analysis, although it is simple enough for a technical or approximate analysis. These procedures will be outlined without recourse to the detailed instruction given in the preceding section, since no new manipulative processes are involved.

The apparatus is prepared for the analysis as before. The distributor and manometer are filled with nitrogen at the compensator pressure. The sample is introduced, adjusted to the compensator pressure, and measured. The volume of this sample will be large, and may be as much as $100 \mathrm{ml}$, depending on the composition of the gas. Of course if the gas were pure $\mathrm{CH}_{4}$, it would be possible to use only a $50 \mathrm{ml}$ sample, since twice this volume of oxygen is required and the capacity of the burette is only $100 \mathrm{ml}$. Furthermore, there is a total contraction of 2 volumes per volume of $\mathrm{CH}_{4}$ burned, so that the volume of the gas after combustion is measurable within the burette. For pure CO, $100 \mathrm{ml}$ of sample might be used, the oxygen required would be only $50 \mathrm{ml}$, and the volume after combustion would be $100 \mathrm{ml}$, and so on. When the approximate composition has been determined, the analyst should compute the maximum permissible volume of sample for further analyses. 
After the sample is measured, the $\mathrm{CO}_{2}$ and $\mathrm{O}_{2}$ are absorbed exactly as before. For a technical analysis the $\mathrm{O}_{2}$ confined below cock 5 with the $\mathrm{CO}_{2}$ absorption may be neglected. For an exact analysis this should be removed by dilution as before.

When the volume has been measured after the absorption of oxygen, and while the pressure is till adjusted, 4 is turned to the position $\perp$. The sample in the burette is then passed into $P_{2}$ for temporary storage, mercury in the burette being taken to the bore of 2 , which is then turned to 3 . Oxygen is then taken into the burette, 4 is turned to the position - , and after an initial approximate adjustment to atmospheric pressure, the burette is opened to the manometer. The volume of oxygen is then measured in the usual manner. Cock 4 is again turned to the position $\perp$ and the oxygen is transferred to $P_{4}$ and 11 is closed. The gas sample is then withdrawn from $P_{2}$ to the burette, the gas contained in the manometer is also transferred to the burette, and the pressures in $P_{4}$ and the burette are adjusted as previously described for the combustion, which is forthwith conducted. The platinum wire is more apt to fuse during a combustion with oxygen, and a more careful control of the rheostat and resultant wire temperature is required.

After the combustion, the contraction is measured as before. The $\mathrm{CO}_{2}$ produced during combustion is then determined by absorption in $P_{2}$, care being taken to remove the $\mathrm{CO}_{2}$ confined in the distributor by passing the gas from the burette (after absorption in $P_{2}$ ) into $P_{4}$, thence back to the burette and again to $P_{2}$. The oxygen not used during the combustion is then determined by absorption in $P_{3}$. These steps suffice for a technical analysis.

The procedure for an exact analysis is quite another affair. After the first measurement of $\mathrm{CO}_{2}$ produced during the combustion, the following steps are taken. The gas is first passed into $P_{4}$, and the combustible portion of the original sample that was confined below cock 5 , after the absorption analysis, is burned over the glowing platinum spiral. The further contraction from this second combustion is measured. Next the $\mathrm{CO}_{2}$ produced by the second combustion is determined by passages into $P_{2}, P_{1}$, and again $P_{2}$. Then the excess oxygen is determined by absorption in $P_{3}$, with passages into $P_{4}$ and $P_{2}$ before the final passage in to $P_{3}$. Finally to complete the already long story, a measured small volume of air is added directly to the sample and the mixture (which is, of course, below its explosion limits) is again passed over the heated wire in $P_{4}$ in order to burn the combustible portion of the gas which was confined below cock 6 at the end of the absorption analysis. Following this third combustion, the contraction is measured; and then the $\mathrm{CO}_{2}$ produced is determined by passages into $P_{2}, P_{4}$, and $P_{2}$, and the excess oxygen by passage into $P_{3}, P_{4}, P_{2}$, and $P_{3}$. The data are then carefully segregated, and the sums of all contractions, $\mathrm{CO}_{2}$ volumes, and $\mathrm{O}_{2}$ volumes are calculated. The analyst will then possibly content himself in the future with technical determinations, and that is a great pity, and prompts further aid. which, it is hoped, may be advanced in the following section. 


\section{ANALYTICAL PROCEDURE; WITH THE CALIBRATED MANOMETER} AND DISTRIBUTOR

Many of the individual steps in the procedures already described may he eliminated if the volumes of the arm of the manometer connected to the distributor and of the several parts of the distributor itself are known. It is possible to determine these volumes by a number of simple methods, several of which will be suggested at the conclusion of this discussion. For the present we will assume that these volumes are known, and assign to them definite values. (These will be taken to approximately equal the values obtained from a calibration of one of the analytical units assembled in our laboratory.)

The largest single volume existing outside of the burette is that of the arm of the manometer which is connected to the distributor. This volume is not an absolutely fixed one, since one of its boundaries is determined by a mercury meniscus which is always adjusted to the same height in the opposite manometer arm, but may vary slightly in height within the distributor arm of the manometer because of a change in the total volume of mercury confined in the manometer with changes of temperature. Such temperature changes are never sufficiently large to affect the pressure balance during the course of a single analysis. A calculation will also show that a change of $10^{\circ} \mathrm{C}$. will not change the volume of gas confined above the mercury within the distributor arm of the manometer by more than 0.01 $\mathrm{ml}$. This volume may, therefore, be accepted as constant as far as the analysis goes. The remaining volumes within the distributor are bounded by the glass walls of the capillaries, with the exception of the gas confined between the reagents of the pipettes $P_{2}$ and $P_{3}$, and stopcocks 13 and 12. Since these reagents are always adjusted to etch marks on capillary stems, the resulting variations in volume are negligible.

These volumes may now be noted.

$D_{1}$, the manometer arm adjacent to the distributor

$m l 10$

$D_{2}$, the capillary space within the distributor from cock 2 through cocks

$4,5,6,13$, and 12 to the etch marks on the capillaries below 13 and 12 -.

$D_{3}$, the capillary spaces within the distributor between cock 5 and the etch marks on the capillaries below 13, and between cock 6 and the etch marks $D_{4}$, the capillary space within the distributor from cock 2 through 4 and $\overline{5}$ to 6 (that is, the horizontal portion of the distributor)

Let us now review the analytical procedures already given and determine how these may be simplified, having at our command the additional information just given.

Modified procedure using air for the combustion.-The technique first described required the use of a fresh portion of sample for the combustion, and this, in turn, made it necessary to replace the gas confined within the apparatus, after the absorption analysis, with nitrogen. These manipulations require some time and trouble which may be saved.

After the absorption analysis, gas is expelled from the burette until only a small portion remains. The volume of this gas retained for the combustion is measured. Let us suppose this volume is $10 \mathrm{ml}$ (which would have been required for the first analysis), while the

"Ordinarily this will be only $1 \mathrm{ml}$. 
volume of the original sample taken for the absorptions was $100 \mathrm{ml}$, and after absorption of carbon dioxide and oxygen was $90 \mathrm{ml}$. The gas within the apparatus has been thoroughly mixed during tho absorptions, so that we have within the distributor and manometer some of the nitrogen they originally contained plus some of the gas sample from the burette, and conversely, within the buret.e we have some of the gas sample it originally contained plus some of the nitrogen from the distributor and manometer. With the discarded portion of gas we have also discarded some of the nitrogen originally present in the distributor and manometer.

The conditions just before the absorption analysis were:

In $B, 100 \mathrm{ml}$ sample.

In $D_{1}+D_{2}, 2.8 \mathrm{ml}$ nitrogen.

The conditions after the absorption analysis and just before expelling $80 \mathrm{ml}$ of the mixture from the burette were:

$$
\begin{aligned}
& \text { In } B\left(\frac{90}{92.8} 90\right) \mathrm{ml} \text { sample }+\left(\frac{2.8}{92.8} 90\right) \mathrm{ml} N_{2} . \\
& \text { In } D_{1}+D_{2}\left(\frac{90}{92.8} 2.8\right) \mathrm{ml} \mathrm{sample}+\left(\frac{2.8}{92.8} 2.8\right) \mathrm{ml} N_{2}
\end{aligned}
$$

The conditions after expelling $80 \mathrm{ml}$ of mixture from the burette are:

$$
\text { In } B\left(\frac{90}{92.8} 10\right) \mathrm{ml} \text { sample }+\left(\frac{2.8}{92.8} 10\right) \mathrm{ml} N_{2} \text {. }
$$

In $D_{1}+D_{2}$ unchanged from the second condition.

$$
\text { In } D_{4}\left(\frac{90}{92.8} 0.4\right) \mathrm{ml} \mathrm{sample}+\left(\frac{2.8}{92.8} 0.4\right) \mathrm{ml} N_{2} \text {. }
$$

Now it would be of advantage to eliminate the necessity of burning the combustible portion of the gas confined below 5 and 6 after the absorption analysis, since, as we have seen during the discussion in section 5, this involves additional tedious steps. We shall, therefore, arrange the procedure so that these gases remain inert and may be considered as so much nitrogen. Furthermore, the gas confined in the manometer may be treated in the same manner. We should then be interested only in the calculations:

$$
\begin{aligned}
& \text { In } B\left(\frac{90}{92.8} 10\right) \mathrm{ml} \text { sample. } \\
& \text { In } D_{4}\left(\frac{90}{92.8} 0.4\right) \mathrm{ml} \text { sample. }
\end{aligned}
$$

The sum of these gives the volume of the original sample (less the $\mathrm{CO}_{2}$ and $\mathrm{O}_{2}$ ) which is taken for, and will react during, the combustion. This volume is $9.57+0.388$, or to reduce within the practical limits of accuracy, $9.57+0.39=9.96 \mathrm{ml}$. Just how the percentages of the combustible components may be calculated will be developed shortly.

After the measurement of this sample, 2 is closed, 4,5 , and 6 are turned to the position $\perp$, and the combustion is then conducted with the manometer shut off. The contraction is measured as before, then $26284^{\circ}-30-11$ 
the $\mathrm{CO}_{2}$ produced and oxygen excess are determined. This greatly simplifies the manipulative procedure, and does not greatly add to the burden of the calculations.

To prepare the apparatus for a second analysis it is necessary to replace the confined gas with $\mathrm{N}_{2}$, since the mixture within the apparatus now contains some proportion of combustible components which have not reacted.

Procedure when oxygen is used for the combustion.-The complication which was involved in this procedure (as described in sec. 5) was the necessity of burning the small portions of gas confined under cocks 5 and 6 at the termination of the absorption analysis. This may now be avoided by subtracting the amount of the original sample confined in these spaces from the total volume of the original sample. If $50 \mathrm{ml}$ of sample was taken, the amount of sample confined in $D_{3}$ is $\left(\frac{50}{52.8} 0.4\right) \mathrm{ml}=0.38 \mathrm{ml}$. The amount of sample burned would then be $50.0-0.38=49.62 \mathrm{ml}$. The gas confined in the manometer is displaced into the burette before the combustion. The combustion is then followed by measurement of contraction, $\mathrm{CO}_{2}$ produced, and excess oxygen, with no complications such as were experienced before. Much time is also saved.

\section{DETERMINATION OF THE STEPS NECESSARY FOR AN ACCURATE ANALYSIS}

The knowledge of the capacities of the manometer arm connected to the distributor and of the various parts of the distributor itself will be of further benefit. The analyst is now in the position to determine just what steps are necessary for an exact analysis. Let us suppose, for example, that $2 \mathrm{ml}$ of oxygen is absorbed from $100 \mathrm{ml}$ of original sample during the first passages from $B$ to $P_{3}$. Shall the analyst pass the gas back into $P_{2}$ to effect the removal of the oxygen confined below cock 5 after the absorption of carbon dioxide? The volume of oxygen which would then be removed by this step, and which might then be absorbed, would be

$$
\left(\frac{2}{100} 0.2\right) \mathrm{ml}=0.004 \mathrm{ml}
$$

This amount could not be measured in the burette, and the extra step may be omitted. Had $20 \mathrm{ml}$ of oxygen been absorbed during the first passages into $P_{3}$, the volume of oxygen confined under cock 5 would be measurable $(0.04 \mathrm{ml})$ and the gas should be removed by dilution for absorption in $P_{3}$.

In a similar manner one may calculate whether or not it is necessary to perform other such steps designed to remove gases confined in the distributor by dilution with gas from the burette. It will usually be necessary to remove $\mathrm{CO}_{2}$ confined in the distributor after the combustion. It will be remembered that a small error in the measurement of total carbon dioxide produced upon combustion will result in a larger error in the calculated composition of the mixture. This will become apparent after reading section 9 , where the equations for calculating the volumes of $\mathrm{H}_{2}, \mathrm{CO}$, and $\mathrm{CH}_{4}$ are given. 
It may be of advantage to tabulate values, or plot them on curves, showing the volumes retained in the various capillary dead spaces as functions of the amounts of each constituent present at any step of the analysis. Data so prepared could be used as a ready reference in determining the number of dilutions necessary. The analyst will probably learn in time to reach these conclusions $b_{y}^{\text {r mental }}$ arithmetic.

\section{CALIBRATION OF THE DISTRIBUTOR AND MANOMETER}

The usefulness of the work discussed in the two preceding sections depends a great deal upon the ease with which the distributor and manometer can be calibrated. It is obvious that the accidental breaking of any part will involve recalibration of the piece used for replacement, and for this reason it should be possible to make the calibration simply and quickly. As a matter of fact, there should be little danger of breakage, and if this does occur it is apt to be an absorption pipette which must be replaced. Fortunately, neither the calibration of the pipette nor of the distributor and manometer, presents any real difficulty.

Calibration of pipettes. - The empty pipette is inverted and the capillary portion connecting to the distributor is immersed in mercury. Reduced pressure is applied to the atmospheric outlet of the pipette reservoir, where the reagent is ordinarily introduced. The stopcock is slowly opened and mercury is drawn into the pipette until it passes about a centimeter beyond the etch marks. The reduced pressure within the pipette is now released, and the mercury is allowed to flow back very slowly through the partially opened stopcock. When the mercury meniscus reaches the etch mark the cock is closed and the capillary tip is removed from the mercury in which it has been immersed. The mercury which is now confined in the capillaries of the pipette is allowed to drain out into a small weighing flask. The weight of the mercury is taken and this is converted to the desired volume, by multiplying by 0.0738 . (Corrections for changes of temperature, etc., are unnecessary for the small volumes of the capillary spaces.)

Calibration of the distributor. - The distributor can be calibrated by the same method. The whole piece is inverted and mercury is introduced from a reservoir temporarily connected by rubber tubing to cock 9 . The distributor is then tilted slightly and the mercury is caught and weighed as it is allowed to escape. The exit flow is controlled by opening the various cocks, and it is thus possible to calibrate each section of the distributor.

There are many alternative methods. One simple method is to mount the distributor vertically and admit water to the various sections from a $10 \mathrm{ml}$ calibrated volumetric burette connected temporarily to cock 9 .

Calibration of the manometer arm connected to the distributor.-This can best be done after the apparatus is assembled and ready for an analysis.

Air is taken into the burette, the pressure is balanced against the compensator by the manometer, and the volume within the burette is read. The manometer is now connected to the combustion pipette by turning cock 4 to the position -1 . $L_{3}$ is placed on $R_{6}$, and a screw clamp which has closed the rubber tubing connecting $L_{3}$ and $P_{4}$ is now very slowly opened until the mercury flows upward in the distributor arm of the manometer. When the mercury thread reaches the bore of 4 , this cock is turned clockwise to position $\vdash$ and the pressure of the gas within the burette is again balanced with the compensator, and the volume measured. The difference between the first and second volumes is the volume of the manometer arm which was sought. The measurement should be repeated several times and an average value taken. 


\section{CALCULATION OF THE ANALYSIS}

We have now obtained the following data:

$V_{1}=$ Volume of the srmple of gas.

$V_{2}=V_{1}$ minus the $\mathrm{CO}_{2}$ absorbed.

$V_{3}=V_{2}$ minus the $\mathrm{O}_{2}$ absorbed.

$V_{4}=$ Volume of oxygen taken for combustion. (If air, multiply by 0.2095 .)

$V_{5}=$ Volume of cas sample taken for combustion.

$V_{6}=\left(V_{4}+T_{5}\right)$ minus the total contraction (TC) after combustion.

$V_{7}=V_{6}$ minus the $\mathrm{CO}_{2}$ produced upon combustion.

$V_{8}=V_{7}$ minus the oxygen left after the combustion, from which the oxygen consumed may be computed.

From these we obtain the volumes

Carbon dioxide $=V_{1}-V_{2}$.

Oxygen $=V_{2}-V_{3}$.

Total contraction $=\left(V_{4}+V_{5}\right)-V_{6}$.

$\mathrm{CO}_{2}$ produced $=V_{6}-V_{7}$.

$\mathrm{O}_{2}$ consumed $=V_{4}-\left(V_{7}-V_{8}\right)$.

The volumes of $\mathrm{H}_{2}, \mathrm{CO}$, and $\mathrm{CH}_{4}$ are computed from equations derived from the reaction equations:

$$
\begin{aligned}
& 2 \mathrm{H}_{2}+\mathrm{O}_{2}^{\prime}=2 \mathrm{H}_{2} \mathrm{O}\left(\mathrm{TC}^{\prime}=3\right) \\
& 2 \mathrm{CO}+\mathrm{O}^{\prime \prime}{ }_{2}=2 \mathrm{CO}^{\prime \prime}\left(\mathrm{TC}^{\prime \prime}=1\right) \\
& \mathrm{CH}_{4}+2 \mathrm{O}^{\prime \prime \prime}{ }_{2}=2 \mathrm{H}_{2} \mathrm{O}+\mathrm{CO}^{\prime \prime \prime}{ }_{2}\left(\mathrm{TC}^{\prime \prime \prime}=2\right)
\end{aligned}
$$

From these equations taken in order it is seen that:

$$
\begin{aligned}
& \mathrm{H}_{2}=2 / 3 \mathrm{TC}^{\prime}=2 \mathrm{O}^{\prime}{ }_{2} \\
& \mathrm{CO}=2 \mathrm{TC}^{\prime \prime}=2 \mathrm{O}^{\prime \prime}{ }_{2}=\mathrm{CO}^{\prime \prime}{ }^{2} \\
& \mathrm{CH}_{4}=1 / 2 \mathrm{TC}^{\prime \prime \prime}=1 / 2 \mathrm{O}^{\prime \prime \prime}{ }_{2}=\mathrm{CO}^{\prime \prime \prime}{ }_{2}
\end{aligned}
$$

Expressing the reaction of the mixture in terms of $\mathrm{TC}, \mathrm{O}_{2}$, and $\mathrm{CO}_{2}$; where TC now equals the total contraction after combustion of the mixture, $\mathrm{O}_{2}$ equals the oxygen consumed and $\mathrm{CO}_{2}$ equals the carbon dioxide produced during the combustion of the mixture:

$$
\begin{aligned}
& 1.5 \mathrm{H}_{2}+0.5 \mathrm{CO}+2 \mathrm{CH}_{4}=\mathrm{TC} \\
& 0.5 \mathrm{H}_{2}+0.5 \mathrm{CO}+2 \mathrm{CH}_{4}=\mathrm{O}_{2} \\
& \mathrm{CO}+\mathrm{CH}_{4}=\mathrm{CO}_{2}
\end{aligned}
$$

Solving ( 7 ) and (8) for $\mathrm{H}_{2}$ :

$$
\mathrm{H}_{2}=\mathrm{TC}-\mathrm{O}_{2}
$$

Solving (S) and (9) for $\mathrm{CH}_{4}$ (substituting $\mathrm{H}_{2}=\mathrm{TC}-\mathrm{O}_{2}$ ):

$$
\mathrm{CH}_{4}=\mathrm{O}_{2}-1 / 3\left(\mathrm{CO}_{2}+\mathrm{TC}\right)
$$

Solving (8) and (9) for CO:

$$
\mathrm{CO}=1 / 3\left(4 \mathrm{CO}_{2}+\mathrm{TC}-3 \mathrm{O}_{2}\right)
$$


Equations (10), (11), and (12) are used to compute, from the observed data, the volumes of $\mathrm{H}_{2}, \mathrm{CO}$, and $\mathrm{CH}_{4}$, in the portion of the sample taken for combustion.

If only $\mathrm{CH}_{4}$ and $\mathrm{H}_{2}$ are present, the equations for their volumes are:

$$
\begin{aligned}
& \mathrm{CH}_{4}=\mathrm{CO}_{2} \\
& \mathrm{H}_{2}=2 / 3\left(\mathrm{TC}-2 \mathrm{CO}_{2}\right)
\end{aligned}
$$

If only $\mathrm{CO}$ and $\mathrm{H}_{2}$ are present, the equations for their volumes are:

$$
\begin{aligned}
& \mathrm{CO}=\mathrm{CO}_{2} \\
& \mathrm{H}_{2}=1 / 3\left(2 \mathrm{TC}-\mathrm{CO}_{2}\right)
\end{aligned}
$$

In either of the above cases, it is not necessary to determine the oxygen consumed. However, if this is done, a further check is afforded, since the calculations may be made upon the basis of TC and $\mathrm{O}_{2}$ as well.

If methane and ethane are the only two combustible gases present, their volumes are computed from the equations:

$$
\begin{aligned}
& \mathrm{CH}_{4}=1 / 3\left(4 \mathrm{TC}-5 \mathrm{CO}_{2}\right) \\
& \mathrm{C}_{2} \mathrm{H}_{6}=1 / 3\left(4 \mathrm{CO}_{2}-2 \mathrm{TC}\right)
\end{aligned}
$$

These calculations may also be checked by computing from TC and $\mathrm{O}_{2}$ and from $\mathrm{CO}_{2}$ and $\mathrm{O}_{2}$. It will be noted, however, that if more than two hydrocarbons are present it is not possible to determine the composition of the mixture by a combustion. In such cases, the mixture may be separated by fractional distillation. ${ }^{20}$

The percentage of nitrogen may be calculated (for a technical analysis) as equal to 100 minus the sum of the percentages of the other components. The actual volumes of nitrogen can be directly measured for an exact analysis. If all of the gas has been passed over the combustion spiral during the analysis, nitrogen alone remains at the end of the analysis, and this is directly measured. If any of the original sample has been confined below cocks 5 and 6 or in the manometer arm, the volume of this portion of the sample which has not reacted during the combustion is calculated and corrected for.

The calculation of the actual percentages of the components is illustrated in the following example.

It will be well to go through an actual calculation, and after this to assume small errors in the gas volumes for each step of the analysis and observe the significance of these errors. For this purpose we shall assume that the analysis has given the following observed gas volumes:

Sample

After absorption of $\mathrm{CO}_{2-15}$

After absorption of $\mathrm{O}_{2}$

Oxygen taken for combustion....... 35

After combustion

After absorption of $\mathrm{CO}_{2}$ produced by combustion After absorption of $\mathrm{O}_{2}$ left after combustion _..................... \&. 45

20 This method is described by Martin Shepherd in B. S. Jour. Research 2 (R. P. 75), P. 1145; 1929; The Separation of Natural Gases by Isothermal Fractional Distillation. 
From these data we can compute:

Volume of $\mathrm{CO}_{2}$ in sample $=99.10-95.15=3.95 \mathrm{ml}$.

Volume of $\mathrm{O}_{2}$ in sample $=95.15-94.65=0.50$.

Total contraction $=94.65+98.35-81.75=111.25$.

Volume of $\mathrm{CO}_{2}$ produced $=81.75-34.40=47.35$.

Volume of excess $\mathrm{O}_{2}=34.40-8.45=25.95$.

Volume of $\mathrm{O}_{2}$ used $=98.35-25.95=72.40$.

Volume of $\mathrm{H}_{2}$ burned $=111.25-72.40=38.85$.

Volume of CO burned $=1 / 3[4(47.35)+111.25-3(72.40)]=27.82$.

Volume of $\mathrm{CH}_{4}$ burned $=72.40-1 / 3[47.35+111.25]=19.53$

The percentages of $\mathrm{CO}_{2}$ and $\mathrm{O}_{2}$ are directly obtained:

$$
\begin{aligned}
& \text { Per cent } \mathrm{CO}_{2}=\frac{3.95 \times 100}{99.10}=3.99 \\
& \text { Per cent } \mathrm{O}_{2}=\frac{0.50 \times 100}{99.10}=0.51
\end{aligned}
$$

To obtain the percentages of $\mathrm{H}_{2}, \mathrm{CO}$, and $\mathrm{CH}_{4}$, a correction must be made for the volumes of these gases which were confined below stopcocks 5 and 6 after the absorption analysis and which, therefore, were not burned during the combustion. The volume of this space was given as $0.4 \mathrm{ml}$. At the beginning of the analysis the apparatus contained $2.8 \mathrm{ml} \mathrm{N}$. After absorption of $\mathrm{CO}_{2}$ and $\mathrm{O}_{2}$ there remained $94.65 \mathrm{ml}$ of gas in the burette. The fraction of the $2.8 \mathrm{ml} \mathrm{N} 2$ which is confined within the $0.4 \mathrm{ml}$ space after the absorption analysis is, therefore,

$$
0.4 \frac{2.8}{2.8+94.65}=0.01 \mathrm{ml}
$$

The $0.4 \mathrm{ml}$ space, therefore, contains $0.4-0.01^{\prime}=0.39 \mathrm{ml}$ of the original sample (less its $\mathrm{CO}_{2}$ and $\mathrm{O}_{2}$ ) which was not burned. The volume of the original sample minus the $\mathrm{CO}_{2}$ and $\mathrm{O}_{2}$ was $94.65 \mathrm{ml}$. Of this, $94.65-0.39=94.26 \mathrm{ml}$ was burned. The volumes of $\mathrm{H}_{2}$, $\mathrm{CO}$, and $\mathrm{CH}_{4}$ found were, therefore, the result of burning $94.26 \mathrm{ml}$ of the original sample. Since $94.65 \mathrm{ml}$ of the sample should have been burned, it is obvious that the observed volumes of $\mathrm{H}_{2}, \mathrm{CO}$, and $\mathrm{CH}_{4}$ are too low. These may be corrected to the basis of the original sample of 99.10 by multiplying each volume by the factor $\frac{94.65}{94.26}$, or the original sample may be corrected to the basis of the observed volumes of $\mathrm{H}_{2}, \mathrm{CO}$, and $\mathrm{CH}_{4}$. The latter method is simpler. The fraction $x$ of the sample which should be used to compute the percentages of $\mathrm{H}_{2}, \mathrm{CO}$, and $\mathrm{CH}_{4}$ from their observed volumes is obtained:

$$
\frac{94.65}{94.26}=\frac{99.10}{x} \text { or } x=98.69
$$

The percentage of $\mathrm{H}_{2}, \mathrm{CO}$, and $\mathrm{CH}_{4}$ are now computed:

$$
\text { Per cent } \mathrm{H}_{2}=\frac{38.85 \times 100}{98.69}=39.37
$$




$$
\begin{aligned}
& \text { Per cent } \mathrm{CO}=\frac{27.82 \times 100}{98.69}=28.19 \\
& \text { Per cent } \mathrm{O}_{2}=\frac{19.53 \times 100}{98.69}=19.79
\end{aligned}
$$

The percentage of $\mathrm{N}_{2}$ in the original sample can also be computed. The volume of the original sample confined within the $0.4 \mathrm{ml}$ space was $0.39 \mathrm{ml}$. Of this volume there were

$$
\frac{38.85+27.82+19.53}{94.26} 0.39 \mathrm{ml}=0.36 \mathrm{ml}^{\circ} \mathrm{H}_{2}, \mathrm{CO} \text { and } \mathrm{CH}_{4}
$$

which were not burned. This $0.36 \mathrm{ml}$ of unburned gas remains at the end of the analysis and is measured with the residual volume of nitrogen. The amount of nitrogen contained in the original sample is therefore the observed residual volume minus the volume of unburned gas, or $8.45-0.36=8.09 \mathrm{ml}$. The percentage of $\mathrm{N}_{2}$ is then calculated:

$$
\text { Per cent } \mathrm{N}_{2}=\frac{8.09 \times 100}{99.10}=8.16
$$

The sum of the percentages of the constituents is now taken:

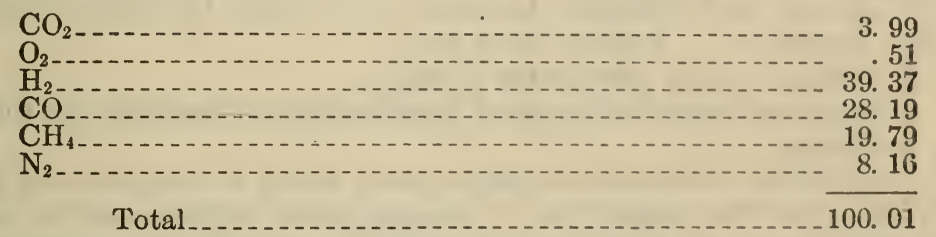

The analyst should determine the significance of errors made in the various steps of the analysis. This can be done by assigning arbitrary errors to the observed volumes and recalculating the results. For example, suppose errors of $0.05 \mathrm{ml}$ had been made in the measurements of the volume after combustion and the volume after absorption of the $\mathrm{CO}_{2}$ produced by combustion, and that these errors occurred in opposite directions. The burette readings are then

$$
\begin{aligned}
\mathrm{ml} & =99.10 \\
-\mathrm{CO}_{2} & =95.15 \\
-\mathrm{O}_{2} & =94.65 \\
+\mathrm{O}_{2} & =98.35 \\
-\mathrm{TC} & =81.70 \\
-\mathrm{CO}_{2} & =34.45 \\
-\mathrm{O}_{2} & =8.45
\end{aligned}
$$

The computed results are:

$$
\begin{aligned}
& m l \\
\mathrm{CO}_{2} & =3.99 \\
\mathrm{O}_{2} & =0.51 \\
\mathrm{H}_{2} & =39.47 \\
\mathrm{CO} & =28.12 \\
\mathrm{CH}_{4} & =19.76 \\
\mathrm{~N}_{2} & =8.16
\end{aligned}
$$

Total 100.01 
Differences of 0.1 per cent $\mathrm{H}_{2}, 0.07$ per cent $\mathrm{CO}$, and 0.03 per cent $\mathrm{CH}_{4}$ were obtained. If the combustion is expected to check within 0.1 per cent it is apparent that the errors in measuring the volumes, which detcrmine the total contraction, $\mathrm{CO}_{2}$ produced, and oxygen consumed, must be small. For example, suppose the $\mathrm{CO}_{2}$ produced upon combustion had been determined by passage into $P_{2}$ alone, rather than by passages into $P_{2}, P_{4}$, and $P_{2}$. The $\mathrm{CO}_{2}$ left in the train and not determined would have been approximately $\frac{47.35}{81.75} 0.3=0.17 \mathrm{ml}$, and this error would have resulted in much larger errors in the calculated results than were obtained in the example given above. Similarly, the oxygen left below cock 5 and in the distributor after the absorption of the $\mathrm{CO}_{2}$ produced on combustion is $\frac{25.95}{47.35} 0.4=0.22 \mathrm{ml}$, and this must be regained by dilution and determined by absorption.

Calculations of this sort will enable the analyst to avoid unnecessary steps on the one hand and deplorable errors on the other.

\section{SUMMARY}

The gas analysis apparatus which has been described possesses a number of new and desirable features and retains the better features of older apparatus. Among them are:

1. A burette which eliminates parallax.

2. A device which provides good illumination for reading the burette with precision.

3. A combined manometer-compensator which is compact and much less fragile than the usual type. The manometer eliminates the significant capillary errors which occur with the variety in common use. The pressure balance is obtained by electric contact, which results in much greater accuracy than is possible with the usual methods, and greater speed.

4. A special control stopcock, which insures not only accuracy in balancing the manometer, but practically eliminates the danger of drawing reagents from the pipettes into the distributor.

5. A water jacket which eliminates the objectionable large rubber stopper ordinarily used.

6. A distributor or manifold which eliminates much of capillary dead space, and is calibrated to permit the use of a special method for exact analysis which makes it possible to obtain accuracy without the usual large number of operations.

7. An absorption pipette in which reaction is very rapid.

8. A combustion pipette which eliminates the many undesirable features of the common type.

9. A sampling pipette which is designed to permit the convenient manipulation of gas samples without possibility of contamination.

10. Means for practically eliminating the leakage which commonly occurs in the ordinary commercial apparatus.

11. An arrangement of assembly which permits unusual conveniences in manipulation. The burette and distributor may be balanced simultaneously against the compensator. The usual error arising from diffusion into the manometer is eliminated. The distributor may be flushed with nitrogen from either end. 
12. An apparatus support constructed entirely of metal which is free from warping or swelling and is designed to make easy the assembly and replacement of all parts of the apparatus.

Several procedures for making technical and exact analyses are given. These procedures depend upon (1) computing the necessary corrections from the observed data and the known calibrition of the distributor, and (2) automatically eliminating these corrections by additional operations within the apparatus itself. Since the former method eliminates many of the operations which are required in the latter, it should prove of decided advantage where accuracy is required and a minimum of time is available, and is perhaps the most hopeful advance to be offered in the operating technique of this kind of gas analysis.

The combination of the improved apparatus and method proceeds along the desirable line of development whose aim is a greater accuracy obtained in a shorter time.

Washington, November 14, 1930. 